\title{
La representación social de los derechos humanos en El Salvadorl
}

\section{Introducción y objetivos}

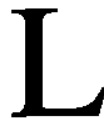

a presente investigación se planteó el objetivo inicial de estudiar la percepción de los derechos del niño en el país y los factores que determinan las posibles estrategias empleadas por los padres para defender esos derechos. Para poder tener un marco general que permitiera comprender mejor la cuestión y, en la creencia de que los derechos del niño constituían un tema que quizás no le fuera familiar a todo el mundo, se optó por estudiar inicialmente la percepción o representación social de los derechos humanos en general y, desde aquí, entrar en la cuestión específica de los derechos del niño. En este artículo se expondrán los resultados sobre los derechos humanos en general y se dejarán para otras ocasiones los referidos específicamente a los derechos del niño.

El concepto de representación social ha sido usado a menudo en las ciencias sociales para abordar la difusión y comprensión por el público en genral de teorías, principios o nociones cuyo contenido exacto, formal y codificado estaba sin embargo sólo al alcance de unos pocos ${ }^{2}$. Este es el caso de las teorlas científicas que pese a ser desarrolladas y comprendidas exactamente solo por unos cuantos especialistas - pensemos por ejemplo en la teoŕa de la relatividaddisfrutan de otra existencia paralela en la comprensión que de ellas tienen los ciudadanos en general. Esta última no puede ser necesariamente tan exacta, detallada y profunda como la de los científicos pero con frecuencia tiene una gran importancia en el impacto que la teoría acaba teniendo en la sociedad y en su percepción del mundo. Por otro lado, las simplificaciones o distorsiones con las que el pensamiento profano hace suyas tales teorlas no son aleatorias sino que responden a las preconcepciones dominantes entre las cuales las nuevas teorías deben encontrar acomodo. El modo en que tales teorias son asimiladas nos revela mucho de la estructura del pensamiento anterior, de la misma forma 
que el conocimiento de ésta podría ayudar a predecir cómo van a ser comprendidas estas nuevas teorías.

En nuestra opinión, los derechos humanos se ajuslan perfectamente a esta descripción. Por un lado, poseen una entidad formal y codificada, plasmada en convenios, internacionales, declaraciones universales y códigos legales, pero por otro lado guardan otra existencia social en la forma en que son comprendidos por el público en general, particularmente en las sociedades donde han alcanzado un puesto destacado en la agenda social y política. Aún más, en los países donde los derechos humanos se encuentran en el centro de la controversia social y política que enfrenta a diversos sectores sociales, como es el caso de El Salvador, es probable que cada sector tenga una imagen distinta e incluso opuesta de los mismos. En definitiva, es previsible que cada sector social posea una representación diferente de los derechos humanos y que estas diversas representaciones se opongan también unas a otras, de forma retórica pero asimismo en cuanto a su aplicación real, dentro del conflicto que enfrenta a tales sectores. Todo ello es especialmente relevante si pensamos que, a diferencia de las teorías científicas cuya ejecución y traducción tecnológica puede discurrir con una relativa independencia de la comprensión pública de las misrnas, el respeto a los derechos humanos dependerá decisivamente de la comprensión de los mismos que tengan los actores sociales.

En suma, la investigación trató de explorar cuál es la concepción de los derechos humanos que tienen los salvadoreños, qué derechos concretos perciben como violados y qué estrategias emplean y favorecen para tratar de eliminar las violaciones a sus derechos. Dado que, de acuerdo a lo referido anteriormente, se prevela que la representación de los derechos humanos iba a variar en gran medida dependiendo de la inclinación política y de la posición en la estructura social, el estudio trató de incluir a personas de distintos sectores sociales, con diferentes preferencias políticas, procedentes de varias regiones del país y pertenecientes a diversas clases sociales.

\section{Metodología}

Para esta primera fase de la investigación se prefirió una técnica más cualitaliva, como el grupo de discusión, que nos permitiera profundizar mejor en las representaciones de los distintos grupos. Esta técnica consiste en reunir a un grupo reducido de personas, relativamente homogéneo, y entrevistarles colectivamente mediante un guión bastante flexible. Así se conforma una entrevista semi-estructurada, en la que los participantes debaten libremente sobre las cuestiones suscitadas, argumentando y contraargumentando unos a otros (de ahr su nombre), en la que el único papel del moderador es proponer los temas, motivar a la participación si no sucede espontáneamente y encargarse de reconducir la 
discusión en los casos en los que derive hacia asuntos notoriamente alejados de los propuestos. Al final de la sesión se resume lo tratado para que los participantes corroboren los contenidos fundamentales tal como han sido interpretados por el equipo. El contenido de la discusión se graba y se analiza posteriormente.

Esta técnica permite recoger el discurso dominante en toda su riqueza, de una manera similar a como se produce en la vida cotidiana, y tener acceso asf a las actitudes y representaciones que están detrás de él. Su naturaleza argumentativa se presta además muy bien al análisis detallado de diferentes alternativas y a la elaboración de un consenso grupal sobre el problema.

El número medio de participantes por grupo fue de unas 10 personas, oscilando entre un mínimo de 6 y un máximo de 15. Los grupos fueron conducidos por un moderador, mientras que el otro miembro del equipo técnico presente se encargaba de tornar notas y resumir las conclusiones al final de la sesión. La duración media de los grupos fue algo inferior a los 90 minutos, la duración máxima fue de algo más de 2 horas.

Los grupos fueron realizados entre la segunda quincena del es de Junio y la primera del mes de Julio de 1993.

El guión de la discusión contenía diversas preguntas abiertas sobre los siguientes temas:

- derechos humanos violados en el contexto de cada grupo

- responsables de esas violaciones

- estrategias de defensa contra las violaciones

- evolución de la situación de los derechos humanos desde la guerra a la actualidad

- validez y legitimidad de distintas instancias gubernamentales, no-gubernamentales e internacionales para la defensa de los derechos humanos.

- derechos de los niños que son violados

— estrategias de defensa de los derechos de los niños

- comparación entre los derechos de los niños y los derechos humanos en general.

3. Descripción de los participantes y resumen de las conclusiones en cada grupo

GRUPO 1. MIEMBROS DE UNA COMUNIDAD CAMPESINA DE ANTIGUOS REFUGIADOS EN UNA ZONA EX-CONFLICTIVA del país y que, por ello, presenta un alto grado de organización interna y una intensa identidad 
política de izquierda. Los habitantes de estas áreas sufrieron directamente una dura represión por parte del ejército al comienzo de la guerra, que se transformó en un hostigamiento más comedido a la vuelta del refugio. Participaron por tanto directamente en las hostilidades, del lado antigubernamental, bien como víctimas civiles, bien como combatientes. Su estatus socioeconómico es muy bajo. Despues de haber sobrevivido en el pasado, tanto en el exilio como a la vuelta al pars, a través de la ayuda internacional y mediante un sistema de producción y servicios fuertemente colectivizado en el que los minimos estaban garantizados, se enfrentan ahora a una nueva fase en la que tanto la producción como los servicios se van 'privatizando' y las ayudas externas tienden a desaparecer. Esto provoca la logica incertidumbre, especialmente entre aquellos que no tienen ingresos fijos y van viendo cómo las subvenciones y servicios gratuitos desaparecen.

Los miembros de la comunidad citan como derechos más violados algunos derechos civiles como los relativos al problema de la documentación y algunos socioeconómicos como el derecho al trabajo, aunque estos últimos no parecen ser percibidos exactamente como derechos humanos en sentido estricto pues se consideran responsabilidad más de la propia comunidad que del estado, en consonancia con la experiencia histórica que han vivido. Del estado se espera más que nada que se abstenga de violar libertades y no se le contempla tanto como proveedor de servicios. Las estrategias de reivindicacion tienen un fuerte componente asociativo y organizativo y responden a las tradición de la izquierda: marchas, etc. Es en cuanto miembros de tales comunidades que las personas ven violados sus derechos y es por tanto tmabién como colectivo como sienten que deben responder. Además, las denuncias ante organismos no gubernamentales y ante las Naciones Unidas, cuyo papel juzgan respectivamente como muy positivo en la moderación de los atropellos del estado, han sidon otro modo importante de hacer valer sus derechos. Por contra, las agencias gubernamentales gozan de una muy escasa credibilidad, determinando un bajísimo grado de legitimidad de un estado que hasta hace poco ha sido su enemigo. En su opinión el gobierno ha estado históricamente para defender sólo a los ricos, a la gente importante, y aún hoy las autoridades locales les ignoran como personas y como comunidad. El estado es pues 'el de los otros' y el necesario grado de adaptación e implantación del estado hasta integrar a la comunidad en el mismo procede con suma lentitud. Precisamente una de las instituciones estatales que más desean tener cerca, la nueva Policía Nacional Civil, aún no se ha desplegado. Esta es una necesidad sentida puesto que la delincuencia aumenta y los viejos mecanismos de control social, con un fuerte control interno, ya no valen en la nueva época.

Si el fin de la guerra ha traído consigo la casi desparición de la represión y con ella un respeto mucho mayor a las libertades civiles (como las de tránsito y de expresión), también ha producido incertidumbre pues en las nuevas reglas del 
juego económicas el sustento ya no está garantizado por la colectividad y debe buscarse individualmente.

GRUPO 2. MIEMBROS DE UN SINDICATO DE OBREROS Y TRABAJADORES URBANOS en general (sobre todo de los sectores de la construcción $y$ textil). Se trata de un sindicato de clase, con una fuerte tendencia reivindicativa y una clara filiación política de izquierda y antigubernamental. De hecho, el mismo sindicato sufrió persecución antes y durante la guerra y algunos de sus miembros murieron a consecuencia de ello.

Son personas de estatus socioeconómico bajo, pero no marginal, con un alto grado de organización social y política.

Los miembros de este grupo reclaman el cumplimiento del derecho a sindicarse y el derecho a la protección legal y la igualdad ante la ley, todos Ios cuales son violados en el contexto laboral. Simplemente formar parte de un sindicato puede significar el hostigamiento o el despido. En menor medida, mencionan como violados el derecho a la vida y otros derechos socio-económicos. De todo esto culpan al gobiemo y a los patronos, que en su visión del mundo están fundidos junto a los militares en un único bloque dominante enfrentado a los trabajadores en la lucha de clases. El estado y sus representantes son más que nada un instrumento de la clase dominante, que ni siquiera cumple las leyes que aprueba y se rige mediante la corrupción y la parcialidad. Ante la indefensión generada, las estrategias se centran en presionar al gobierno a través de instancias no gubernamentales e internacionales y, sobre todo, a través de acciones colectivas como huelgas y manifestaciones. La existencia de una organización colectiva es indispensable y de su unión y amplitud va a depender su capacidad de presionar al gobiemo. El fin de la guerra ha trafdo consigo la desaparición o cuando menos un gran descenso de las violaciones más gruesas contra el derecho a la vida y a la integridad personal, pero no ha conseguido menguar otros muchos tipos de violaciones. Tienen fe en las elecciones como un medio para cambiar a los reclores del sistema político y a las propias reglas del juego, de modo que se logre una paz auténtica y se le confiera al estado una legitimidad de la que hoy carece.

GRUPO 3. ESTUDLANTES DE UNA UNIVERSIDAD PUBLICA, MIEMBROS DE UNA ASOCIACION ESTUDIANTIL DE FILIACION POLITICA DE IZQUIERDA. Dado que dicha universidad está dominada políticamente por las fuerzas de izquierda, su inclinación política es también claramente de izquierda y opuesta al régimen. Sin embargo, a diferencia de los dos grupos anteriores, su estatus socioeconómico es medio o, como mínimo medio-bajo, y su nivel cultural es obviamente mucho mayor que el de los dos anteriores. Por el contrario, su grado de organización social y política no es tan alto.

Los miembros de este grupo enumeran una serie de derechos humanos violados, entre los que destacan el derecho de asociación y sindicación, la libertad de 
expresión y el derecho al trabajo. Se destaca que aunque la situación del derecho a la vida y a la integridad personal ha mejorado con el fin de la guerra, el balance general sobre derechos humanos sigue siendo muy negativo porque el resto de los otros derechos, especialmente los socioeconómicos, continúa en el mismo estado de postración. En su opinión, la clase dominante se sirve del gobiemo, cuyo partido domina los tres poderes y de la judicatura, mediante el soborno y la prevaricación, para mantener sus privilegios y contener las demandas de la clase baja. Se denuncia la falta de igualdad efectiva ante la ley. Ante esta situación las demandas sociales deben recurrir a la presión de los organismos no gubernamentales y de las instancias intemacionales, además de usar los métodos de acción colectiva típicos en la izquierda. En el pasado, la dureza del sector dominante y su disposición a emplear la represión violenta mediante los militares habrían llevado a los sectores populares a la lucha armada como única estrategia posible. Ahora, tras una guerra y un acuerdo de paz en los que no se habría logrado demasiado, piensan que la represión no ha desaparecido aunque se ha hecho por lo general más suave y afirman que el conflicto continúa por otros medios. La solución debería pasar por la educación de la gente para que conozca y reclame sus derechos y pueda desmontar el sistema de dominación política.

GRUPO 4. MIEMBROS DE UNA COMUNIDAD MARGINAL URBANA EN SAN SALVADOR, COMPUESTA POR DESPLAZADOS POR LA GUERRA CON UN GRADO INCIPIENTE DE ORGANIZACION SOCLAL. Se trata de desplazados que luvieron que dejar sus zonas de origen, muchos de ellos en otras áreas del gran San Salvador, debido al conflicto. Guiados por un organismo no gubernamental de izquierdas, ocuparon este solar vacío rodeado de viviendas de clase media e incluso media-alta. Sus viviendas provisionales carecen de muchos servicios y sus habitantes están a la búsqueda de conseguir viviendas definitivas. Su grado de organización social no es muy desarrollado y existe una cierta descomposición social. Esto, unido a la heterogeneida de la población, hace que su inclinación política no sea ni mucho menos tan clara ni tan homogénea como su origen de desplazados y el tipo de organización que les orientó pudiera llevar a pensar. Su estatus socioeconómico es muy bajo y consiguientemente su nivel cultural también muy bajo.

Las violaciones citadas por los miembros de la comunidad se centran en los derechos socioeconómicos y sobre todo en la falta de una vivienda adecuada, ya que desde que la guerra los desplazó y ocuparon el terтeno viven en champas y no se ha resuelto su problema habilacional. Se quejan tabién de la falta de igualdad y de respeto con que son tratados por las autoridades y por los vecinos de clase media y alta que tratan de echarlos de allí. El gobierno y la clase a las que éste represenla son vistos como los principales responsables de su marginación y de este hostigamiento a que se ven sometidos. Por ser desplazados son a menudo acusados de gucrilleros y no les es fácil hallar trabajo. Para delender 
sus derechos recurren a marchas y cartas de protesta, ya que el aparato del estado les resulta ineficaz y corrupto, particularmente en el caso de los jueces. La organización social y la unión son vistas como factores muy importantes para enfrentar sus problemas, pese a que el distinto origen de sus habitantes y sus distintas actitudes sociopolíticas, entre otras cosas, provocan algunos problemas internos. En relación al tiempo de la guerra perciben que se ha mejorado en cuanto al derecho a la vida y a la libre expresión; ya no hay tantas muertes y se sabe dónde ir a reclamar contra los atropellos. Las Naciones Unidas habrían jugado un papel importante en esta evolución y en el surgimiento de los 'derechos humanos', palabras que parecen indicar tanto un concepto que antes parecería que no existía, como también las personas e instituciones que velan por los mismos. Sin embargo, en el campo de los demás derechos, especialmente los socioeconómicos, la situación no ha concluido y sigue siendo muy negativa. Para mejorar, sugieren la elaboración de proyectos de desartollo y la petición de ayuda externaque los saque del ambiente de autodevaluación, resignación y pasividad en que se encuentran, el cual contrasta con su actitud reivindicativa en algunas cuestiones concretas.

GRUPO 5: MIEMBROS DE UNA COMUNIDAD MARGINAL URBANA EN SAN SALVADOR PRACTICAMENTE SIN ORGANIZACION SOCIAL. Se trata de otra comunidad urbana marginal en el noroeste de San Salvador, con viviendas de muy baja calidad en una zona que carece de muchos servicios públicos y de equipamientos urbanos. Aunque tienen una directiva comunitaria reciente, su grado de organización social es mínimo y el grado de participación de los miembros en la misma muy reducido. Algunos miembros de la comunidad trabajan como asalariados y empleados, pero muchos subsisten gracias a actividades marginales. Paralelamente, el nivel de delincuencia en la zona es alto. En principio, los miembros de la comunidad no tienen una adscripción política clara ni uniforme. Su estatus socioeconómico es obviamente, bajo o muy bajo.

Los habitantes de esta comunidad conciben los derechos humanos en términos de respeto mutuo entre individuos. Los derechos violados que consideran como más importantes se refieren al derecho a la integridad, la propiedad y la vida, lesionados por la frecuente delincuencia reinante en su zona. En segundo lugar se refieren a derechos socioeconómicos insatisfechos, como el desempleo o las malas condiciones laborales. La culpabilidad de la situación recae sobre la guerra y sobre otras causas lejanas como la deficiente educación. El temor a represalias y el mal funcionamiento del aparato formal de control social (jueces, policla, etc.) hacen que ni siquiera las violaciones más gruesas sean denunciadas, generando un clima de pasividad, impunidad y fatalismo, y una situación de gran anomía. La precaria organización y unión internas y la falta de tradición reivindicativa los aleja de estrategias de presión colectivas de las que desconfían, mientras la sensación de marginación a manos de los poderosos y la 
autodevaluación les empujan a solicitar instancias externas que sean portavoces de sus reivindicaciones.

Las instituciones oficiales, que los ignoran y a veces son comuptas, no merecen su confianza, pero tampoco las no gubernamentales, a las que no parecen conocer bien. Tan sólo los organismos internacionales les dan una impresión positiva como instancias a las que acudir. El haber estado relativamente apartados de los dos bandos en conflicto y de las fricciones directas provocadas por la guerra les hace pensar que, aunque ahora hay más libertad de expresión y más organismos a los que recurrir en caso de atropello, la situación de los derechos humanos ha empeorado por la carestía de la vida.

GRUPO 6: JORNALEROS Y PEQUEÑOS PROPIETARIOS DE UN CANTON RURAL EN ZONA NO EX-CONFLICTIVA, CON ESCASA ORGANIZACION SOCIAL. Habitan en un lejano cantón del oeste del país y combinan el cultivo de su pequeña propiedad con el trabajo de jornaleros. El extremo aislamiento de la zona donde viven y sus malas comunicaciones les han permitido vivir bastante al margen del conflicto bélico que se vivía en el país, pero también les han privado del acceso a biene.s y servicios y a la propia información en general. Viven en comunidades algo dispersas en el cantón y aunque cuentan con directiva comunitaria, su grado de organización así como sus contactos con el exterior son todavía reducidos. El estatus socioeconómico de esta población es tan bajo que por su nivel de vida podría ser encuadrado dentro del sector marginal. Al igual que en el grupo anterior, sus simpatías políticas no están definidas de antemano.

Los derechos humanos son comprendidos no sólo en su sentido estricto sino también en términos de armonía interindividual. Los derechos violados, en un entorno de extrema pobreza, se centran sobre todo en el aspecto socioeconómico, de lo cual culpan al poder político y al azote impersonal de la pobreza. Se quejan particularmente de que la falta de control de precios les coloque en una situación inerme en el mercado, forzados a comprar insumos caros y obligados a vender barato productos que serán revendidos a un precio muy superior. Ante este panorama, su reacción es de fatalismo e indefensión, y sus estrategias, que consisten en cultivar más o menos teneno según los precios, de mera supervivencia. A la actitud de resignación contribuye la falta de una organización social cohesionada y la ausencia de tradición reivindicativa que les hace desconfiar de los métodos de presión colectiva. El grado de legitimidad del aparato del estado es en estas comunidades bastante bajo, puesto que como campesinos pobres se sienten objeto de una marginación histórica de la que no esperan que este ni ningún gobierno los saque a corto plazo. El aislamiento de la comunidad les ha impedido conocer organismos no gubernamentales o internacionales en los cuales apoyarse para reivindicar sus derechos o lograr un mayor desarrollo. Aunque consideran que el fin de la represión ha acabado con las peores violaciones a los 
derechos humanos acaecidas durante la guerra, que ellos vivieron de cualquier modo de forma relativamente liviana, la postración de los derechos socioeconómicos y el auge de la delincuencia, que se presenta como una continuación del conflicto y que castiga a los más débiles, impiden un balance optimista.

\begin{abstract}
GRUPO 7: MIEMBROS DE UNA COOPERATIVA AGRARIA RELATIVAMENTE PROSPERA EN ZONA NO EX-CONFLICTIVA. Su grado de asociación se reduce a lo laboral y, en comparación a las otras comunidades rurales de su entorno, su nivel de vida es relativamente alto aunque su nivel cultural sigue siendo escaso. Podríamos hablar de un estatus socioeconómico medio, siempre pensando en un hábitat de tipo rural. Su posicionamiento político no puede ser dado por supuesto de antemano.
\end{abstract}

Las quejas más sentidas en relación a los derechos humanos se centran sobre todo en la delincuencia, a través de la cual se lesionan los derechos a la integridad personal, a la propiedad y a la protección de la ley. No hay tampoco igualdad ante la ley, que es administrada fraudulentamente para beneficio de los más ricos. Por último, los derechos socioeconómicos no son satisfechos por culpa, por ejemplo, de la falta de control de precios, tal como señalaba en el grupo anterior.

Dos concepciones sobre los derechos humanos, en el fondo antitéticas pero no polémicamente contrapuestas, conviven en el mismo grupo, y a menudo en boca de las mismas personas. La primera, análoga a la de la mayoría de los grupos que hemos visto hasta ahora, cree que la presión externa ha logrado que el gobierno respete mucho más los derechos humanos, sobre todo en lo relativo a las violaciones más gruesas. En cambio la segunda, enfrentada al pensamiento dernocrático, entiende los derechos humanos más que como derechos propiamente dichos como una ideología de reciente creación, responsable de dar los mismos derechos a la gente honrada que a los delincuentes y dificultando asI la lucha contra la delincuencia.

Esta dualidad se extiende asimismo a otras cuestiones, como la evolución de los derechos humanos desde la guerra a la actualidad (una gran mejora contra un empeoramiento por la delincuencia) o la conveniencia de usar métodos de presión colectiva (son válidos y no hacen caso si no se recurre a ellos contra algo que degenera en alboroto y violencia). Enfrentados a la marginación del estado pero con una posición económica relativamente desahogada que les hace tener actitudes como las de pequeños propietarios, y con una fuerte demanda de ley y orden, los participantes se debaten entre posturas opuestas. En un lugar donde no sufrieron directamente el azote de la guerra, presumen de su neutralidad como grupo (cooperativa) a la que agradecen la ausencia de conflictos y desconfian de la política como una actividad sospechosa. 
Responsabilizan de las violaciones de derechos humanos al gobierno, pero también a la gente en general, a la que debe darse enseñanza en cuanto a derechos humanos. No hay una estrategia clara para enfrentar las violaciones; aisladamente se mencionan posibles opciones, de nuevo contrapuestas, como aumentar la presión externa sobre el gobierno por un lado, o la autodefensa violenta contra la delincuencia por otro. La legitimidad del aparato del estado es baja y los organismos no gubernamentales no gozan de una imagen clara; las instituciones internacionales sí son vistas como una salida en los casos en que el atropello provenga del estado.

GRUPO 8: PROFESIONALES URBANOS DE CLASE MEDIA DEL SECTOR SANITARIO, SIN UNA AFILIACION POLITICA, SINDICAL O SOCIAL PREDETERMINADA. Se trata de profesionales de la salud que trabajan en un ho.spital: médicos, enfermeras y trabajadores sociales. No hay constancia previa de su pertenencia a ninguna organización social, laboral o política. Representan a la clase media urbana, con un nivel cultural relativamente alto, y los miembros de más estatus dentro del grupo (médicos) pueden ser encuadrados en la clase media-alta, con tendencias por tanto presumiblemente más conservadoras. El tipo de urabajo que realizan, en un hospital público, los pone en contacto con personas de diversos estratos sociales desde los medios hasta los más bajos.

La concepción que este grupo tiene de los derechos humanos se acerca a una visión más ortodoxa en la que la responsabilidad recae en el estado, que está obligado constitucionalmente a proporcionar un mínimo bienestar socioeconómico a sus ciudadanos. El derecho individual que es más frecuentemente señalado como violado, de acuerdo a la actividad profesional de los participantes, es la salud, aunque predomina la opinión de que la totalidad de los derechos están insalisfechos. Otros ejemplos que aparecen son los derechos laborales, la educación, los derechos socioeconómicos en general y la inseguridad producto de la delincuencia.

No se cuenta con una estrategia definida para enfrentar las violaciones a los derechos humanos, al margen de mejorar la educación de la población tanto en general como específicamente en cuanto a los derechos humanos. De hecho, ha sido en su opinión la mayor difusión de los derechos humanos en los últimos tiempos la que ha permitido, junto a la presión internacional y a las nuevas condiciones de la posguerra, que mucha gente pueda ahora reclamar sus derechos. La evolución positiva se limita sin embargo a la libertad de expresión y a otras libertades civiles, cuya importancia no esconde sin embargo el estancamiento de los derechos socioeconómicos.

Este sector social, y especialmente los miembros de mayor estatus socioeconómico, desconfía de las estrategias reivindicativas típicas de la izquierda, como huelgas o manifestaciones. En efecto, acuñan el término de 'libertinajes humanos' para designar los des6rdenes supuestamente provocados por el abuso 
de las libertades que ha traído consigo el mayor respeto a los derechos humanos. Por su posición relativamente acomodada y su notable apego al orden, por un lado, y por su sensibilidad a los problemas sociales por otro, tienden a mostrarse como equidistantes ante los atropellos de una y otra pare, gobierno e izquierda, que perjudican por ambos lados a la gente 'nomal' como ellos.

No otorgan legitimidad al aparato del estado, al que acusan de inhibición e ineficiencia más que de comupción, pero tampoco confían en unos organismos no gubernamentales que perciben escorados hacia la izquierda. La Organización de las Naciones Unidas es juzgada como importante en cuanto a su papel pero como desigual en su desempeño.

Su equidistancia ante ambos bloques y su desafección ante las organizaciones en general lo convierten en un sector muy desestructurado, sin afiliación u organización grupal, y con un fuerte rechazo hacia la política como actividad y hacia los políticos.

GRUPO 9: ESTUDIANTES DE UNA UNIVERSIDAD PRIVADA DE TENDENCIA CONSERVADORA CON UN ALUMNADO DE CLASE MEDIA-ALTA Y ALTA, SIN AFILIACION POLITICA O SOCLAL CONOCIDA. Es una considerada de élite entre las que hay en el país. Constituyen el grupo espejo del grupo 3 (estudiantes de una universidad pública). Comparten con ellos su juventud y su alto nivel cultural pero, debido a su extracción social (media-alta y alta) y a la propia orientación de la universidad, discrepan frontalmente en cuanto a su orientación política que en este caso es claramente conservadora. No consta su pertenencia a ningún tipo de organización.

Este grupo presenta un concepto más sofisticado de los derechos humanos, en el que se encuadra la noción de garantías que el estado está obligado a proporcionar. Se destaca la importancia de la educación en derechos humanos y se afirma, dentro de una especie de pedagogía del intercambio, que la única forma de que la gente aprenda a respetar los derechos de los demás es comenzar por respetarle los suyos. Sin embargo, y pese a que reconocen los abusos gubernamentales contra los derechos humanos, su posición ideológica les hace poner el énfasis en los atropellos de la guerrilla, que en su opinión no han sido suficientemente expuestos. Así, inuchos comparten la idea de que la noción de derechos humanos ha sido manipulada en el país para beneficio de la izquierda, hasta tal punto de que el término ha llegado a asociarse con dicha inclinación ideológica.

El punto concreto que más le preocupa es la inseguridad y la falta de protección a raíz de la delincuencia que se ha desatado debido al fin de la guerra. Mientras que esta última era un peligro más o menos lejano, la delincuencia es vivida como una amenaza más difusa e incontrolable y por lo tanto más cercana, por lo que el balance de los derechos humanos tras la guerra no es positivo a pesar de una mayor libertad de expresión y del fin de algunas de las violaciones 
más brutales. En este sentido, señalan que en la posguerra el énfasis oscila hacia otros derechos que antes estaban oscurecidos por los más elementales.

Denuncian que la falta de protección estatal y la corrupción e ineficacia del aparato del estado provocan un clima de anomfa en el que cada uno intenta buscarse la justicia por su mano.

No tienen confianza pues en los organismos oficiales que carecen de legitimidad (excepto quizás la Procuradurfa de Derechos Humanos), pero tampoco en los no gubernamentales ni en los internacionales. Estos estudiantes forman parte de un sector poco estructurado socialmente y sin muchas alternativas ni estrategias para la defensa de sus derechos, aunque las violaciones que sufren son limitadas dada su posición en la estructura social. Su visión de la misión de ONUSAL es particularmente negativa, asociándola con abusos contra los derechos humanos (aunque sólo citan algunos casos relativamente anecdóticos como atropellos viales y un caso de venta de droga) y con privilegios en relación a los salvadoreños, todo lo cual les privaria de legitimidad para ejercer una labor de promoción de los derechos humanos. Las acciones directas, como huelgas y manifestaciones, son ajenas a su socialización política e ideológica, y son vistas en consecuencia como fuentes de disturbios y como propias de gente de bajo nivel, aunque se admite implícitamente que este tipo de gente no tiene tampoco otras alternativas.

La única propuesta que avanzan es mejorar la educación en derechos humanos, de modo que se espera que su mayor conocimiento y difusión mejoren por sí mismos la situación.

GRUPO 10: MIEMBROS DE UN CLUB SOCIAL DE CLASE ALTA, COMPUESTO POR COMERCIANTES Y PROFESIONALES DE INCLINACION POLITICA MUY CONSERVADORA, AUNQUE SIN OTRA AFILIACION POLITICA O SOCIAL CONOCIDA. Se trata de una asociación recreativa y de caridad pública en el este del pals a través de la cual fueron contactados los participantes. Su estatus socioeconómico es alto; son propietarios de negocios, industrias o tierras y consiguientemente su posición política es muy conservadora. No se les conoce pertenencia a otra organización social o política fuera de esta organización de caridad.

Los miembros de este grupo mantienen una actitud muy negativa ante los derechos humanos, que son vistos como símbolo, si no como causa, de todo lo negativo que para ellos ha tenido la evolución política y social del país en los últimos años: la ubicuidad de la delincuencia y las ventajas concedidas a la guerrilla en los acuerdos de paz. Los más moderados consideran que los derechos humanos entendidos literalmente son aceptables y que han colaborado por ejemplo en el descenso del militarismo en el país, pero han sido sin embargo politizados y manipulados para beneficio de los izquierdistas y los delincuentes, 
a quienes no se puede perseguir adecuadamente por culpa precisamente de tales derechos humanos. Los más extremos, que constituyen el discurso mayoritario, rechazan directamente la noción misma y aun las mismas palabras 'derechos humanos', cuya sustitución se pide en aras de otros términos supuestamente más neutrales y fraternales. En esla concepción, los derechos humanos no serían tales derechos reconocidos en un momento del tiempo sino una creación ideológica para favorecer a delincuentes y subversivos en contra de ellos, la parte del país productiva y respetuosa con la ley o al menos con la propiedad privada. En numerosas ocasiones el término 'derechos humanos' parece designar no un principio abstracto sino simplemente un grupo de personas: los grupos de defensa de los derechos humanos y especialmente los internacionales como ONUSAL. En definitiva, los derechos humanos serfan una invención extranjera, probablemente norteamericana, con la finalidad de intervenir e interferir en El Salvador con las peores intenciones. Esta conspiración extranjera, estimulada por un nacionalismo que siente a su país injustamente tratado respecto a los palses poderosos, que también tienen sus problemas sociales sin que nadie vaya a decirles cómo tienen que solucionarlos, sería responsable de casi todos los males nacionales, desde la guerra a la corrupción.

A pesar de su profunda oposición a la izquierda, tanto a sus métodos como a sus objetivos, el grado de legitimidad que estas personas confieren al eslado es casi tan bajo como el que encontrábamos entre los grupos de inclinación izquierdista. El aparato del estado ha sido absentista, ineficaz y corrupto, la ley nunca se ha cumplido, y el amiguismo, la arbitrariedad y el militarismo han hecho estragos en la sociedad civil. Incluso entre ellos mismos que pese a su ascendencia no forman parte de las reducidas capas sociales que han tenido acceso al poder polílico o económico. En esta contradicción, es entendible que mientras denuncian la ineficacia de los mecanismos judiciales, algunos subyacen con orgullo cómo los magistrados de la Corte Suprema resisten en sus puestos ante el acoso internacional.

La corrupción e inhibición del estado desata un alto grado de anomía social del que algunos quisieran salir entrando en un estado de derecho, mientras que otros añoran los tiempos de la ley del más fuerle en los que podían usar la fuerza sin ningún control público (por ejemplo para matar a los ladrones que entraran en su propiedad). El único derecho humano que prácticamente es mencionado es la inseguridad producida por la delincuencia, que provoca que para ellos la situación en la posguerra sea claramente peor que durante la guerra, la cual no les afectó demasiado en su medio urbano. En su opinión, la culpabilidad de esta situación es sólo indirectamente del gobierno pues son las interferencias $y$ las ataduras internacionales las que no lo dejan trabajar con eficacia.

Ante los atropellos que sufren o puedan sufrir no parecen tener otras opciones que la impotencia o la ley del más fuerte, dada su falta de credibilidad en los 
organismos gubernamentales, su rechazo frontal a los organismos no-gubernamentales e internacionales que defienden precisamente a los delincuentes, y su desconfianza hacia la política y los políticos en general y a los métodos reivindicativos de acción directa en particular.

Al igual que aparecía en otros grupos conservadores, surge la idea de que la ayuda de los organismos internacionales lo que provoca es falta de ganas de trabajar entre los beneficiarios.

\section{Representaciones sociales de los derechos humanos}

A) Concepciones o definiciones sociales de los derechos humanos

Teniendo en cuenta el discurso y las actitudes expresadas por cada uno de los grupos pueden dislinguirse las siguientes concepciones diferentes de lo que serían los derechos humanos:

1. Una concepción que hemos dado en llamar ortodoxa, es decir que percibe los derechos humanos como derechos y garantías que el estado debe satisfacer y proveer a los ciudadanos y de cuyas violaciones es por tanto único responsable, tanto en lo que se refiere a los derechos civiles y políticos como a los sociales y económicos.

Esta visión es bastante inusual, sobre todo formulada explícitalmente, y especialmente en referencia a los derechos socioeconómicos que con frecuencia no suelen ser percibidos como una responsabilidad del estado. Se da sobre todo en los sectores más educados y, en menor medida, en sectores de obreros urbanos organizados en una opción de izquierda, que a veces han tenido la oportunidad de seguir cursos de capacitación sobre derechos humanos.

"La verdad es que el responsable de satisfacer los derechos humanos es el estado asi definitivamente, es el único violador también." (GRUPO 8)

"El ladronismo es parte de ellos, porque si hubieran digamos fuentes de trabajo, como dice el compañero, que el gobierno tiene la plena obligación de generar empleo. Otra cosa, la educación... Es mejor para el gobierno que sean ladrones y no que hubieran luchado en contra de ellos." (GRUPO 2)

Los sectores que comparten esta representación, cuando se les pregunta por derechos concretos que son violados en el país, aportan generaimente una larga lista que incluye tanto derechos civiles y politicos - la igualdad ante la ley-. como socioeconómicos —el derecho al trabajo, la salud o la educación.

"Supuestamente se ha venido manejando de que a nivel nacional e internacional los derechos humanos han disminuido pero han disminuido ien qué sentido? El sentido de la tortura, si bien es cierto, la tortura ha 
disminuido de alguna u otra forma. La represión de tipo militar, bueno, excepto la que acaba de haber hace poco [manifestación de los lisiados]. Pero a nivel general los derechos humanos no consisten solamente en andar sacando gente de sus casas, o andar torturando, o andar desapareciendo. Los derechos humanos es algo bien global ... hoy no los torturan, sí, pero están muriendo de hambre. " (GRUPO 3)

2. Una percepción de los derechos civiles y políticos. pero no de los socio-económicos, como responsabilidad del estado. Asf, el estado es visto mús bien como una entidad que debe respetar una serie de libertades, antes que proveer una serie de beneficios. En este sentido, el rol del mismo es más bien pasivo que activo, se le valora por lo que deja de hacer más que por lo que pueda hacer. Esto es tanto más comprensible en un contexto como el pasado reciente en El Salvador, en el que el estado ha estado comprometido activamente en numerosas violaciones a los derechos humanos más elementales.

Esta representación es por ejemplo muy clara en el grupo 1, una comunidad de antiguos refugiados que ha vivido desde siempre al margen del estado, o contra él. La escasa implantación que ha tenido históricamente el aparato del estado en su zona, y su aprovisionamiento de bienes y servicios a través de la ayuda internacional desde la época del refugio a nuestros días, coadyuvan a que los miembros de la comunidad asignen la responsabilidad para la satisfacción de las necesidades socio-económicas a la propia comunidad o a sus líderes, mientras lo que esperan del gobiemo es un cese del antiguo hostigamiento y un trato igualitario. Entre los derechos concretos violados mencionan los problemas con la tierra, pero es destacable que la reclamación no surge tanto porque el estado sea visto como un proveedor obligado de recursos para una vida digna del campesino, que equivaldría a un derecho socio-económico, sino por el incumplimiento de los acuerdos sobre tirras que el propio gobierno firmó en los Acuerdos de Paz.

En menor medida, esta representación asoma también en el discurso del grupo 7, la cooperativa campesina de un nivel económico medio. Sus quejas más sentidas en relación a derechos violados se refieren a la falta de protección conira la delincuencia y a la ausencia de control de precios. En este último caso, de nuevo no se espera que el estado provea nada sino que regule unas condiciones en las que los actores del sistema económico puedan relacionarse entre sí de manera más justa.

3. Los derechos humanos entendidos como una armonía entre los ciudadanos, a nivel interindividual. Los derechos humanos serían pues respetados a medida que las personas se comportaran de manera respetuosa unos con otros, y violados en la medida en que esto no sucediera.

Esta visión es común en comunidades marginales, tanto urbanas como rura- 
les, especialmente en aquellas en las que el grado de anomía y descomposición interna es muy alto.

"Yo digo que derechos humanos es que nos sepamos entender todos, que andemos unidos unos con otros... buenos vecinos, buenos hermanos con toda la gente. " (GRUPO 5)

"Los derechos humanos es el respeto a las demás personas." (GRUPO

5) "Como quiero el bienestar para los demós, lo que voy a hacer en vez de dañar a otro, voy a procurar ayudarle, verdad. Eso es trabajar con los derechos humanos. Porque si yo vengo y daño a otro, yo no estoy trabajando con los derechos humanos. Porque si mi persona viene y va a dañar a otro, alli estoy violando los derechos humanos, alli yo lo que estoy haciendo es violar la ley de los derechos humanos. "(GRUPO 6).

Dado que los derechos humanos consisten en una relación armónica entre las personas, la responsabilidad por las violaciones recae lógicamente sobre los propios individuos, como en el caso de la delincuencia, o a lo sumo sobre la propia comunidad. Esta autoatribución de culpa está ligada frecuentemente a una baja autoestima y a una autodevaluación provocada sobre todo por su reducido nivel cultural.

Las violaciones concretas que suelen mencionarse se refieren pues a la inseguridad provocada por la delincuencia, y a la pobreza en general. En algunas comunidades rurales (grupo 6) también se resalta la falta de regulación de precios, compartiendo en parte la concepción descrita anteriormente de esperar del estado al menos una regulación de las relaciones entre los individuos.

4. En esta concepción, los derechos humanos serían aceptables en su sentido estricto, pero habrían sido manipulados por la izquierda en beneficio de la subversión y de la criminalidad, tal que el propio concepto habría quedado irremediablemente unido a la izquierda, al menos en El Salvador.

Esta representación es común en general en personas de orientación política de derecha y entre los sectores de clase media-alta y alta (grupos 9 y 10), pero también se da en fracciones pertenecientes a la clase media conservadora (un sector importante de los cooperativistas agrarios del grupo 7).

"Ilos derechosl pueden ser manipulados... Por eso es que el tema derechos humanos aquí en El Salvador hasta hace poco ha sido tabú, ha sido sinónimo de izquierda " (GRUPO 9)

"En nuestro medio considero yo particularmente que hay mucha gente haragana que se ha protegido bajo esa palabra de derechos humanos, verdad, para hacer reclamos, para hacer toda índole de... Sin embargo, yo creo que los derechos humanos, si nos apegamos a lo que la ley, y los derechos internacionales como son, deberian de existir, deben existir, es 
lo mínimo que puede existir para un ser humano. Pero también a veces se maneja demasiado la palabra derechos humanos para fines políticos, para fines de toda indole. Yo creo que ahi también hay una..., habria que diferenciar a qué derechos humanos vamos a platicar, a qué derechos humanos queremos. Eso es lo que yo siento, que la gente que se quiere aprovechar ocupa los derechos humanos como para defenderse". (GRU. PO (0)

Parte importante de esta visión es la convicción de que los derechos humanos otorgan 'demasiados derechos' a los delincuentes y por tanto dificultan indebidamente su persecución y su castigo. Los sectores más extremos dicotomizan su percepción del mundo en dos -ellos, las personas decenles, y los delincuentes- y no comprenden por qué ambos colectivos deben de gozar de los mismos derechos. En el fondo, esta actitud es ajena al pensamiento dernocrático y conuraria al núcleo mismo de la idea de los derechos humanos: derechos que tiene cada persona por el mero hecho de ser persona, al margen de sus características $y$ aun de sus acciones.

Entre las violaciones a los derechos humanos más comúnmente señaladas por estos grupos destacan las originadas en la inseguridad provocada por la delincuencia, que es lo que más les preocupa. Por otro lado, su nivel de vida acomodado les invita a ignorar los derechos socioeconómicos como problema.

5. Los derechos humanos corno una creación ideológica reciente cuyo resultado y quizás cuyo objetivo es proteger a los delincuentes o subversivos. A diferencia del caso anterior, no se trata de que hayan sido manipulados o usados para un fin ajeno a su proposito original sino que los derechos humanos son intrínsecamente rechazables en sí mismos. Encontramos esta posición fundamentalmente en personas de clase alta con una orientación política más derechista (grupo 10), aunque también asoma en fracciones de la clase media conservadora (grupo 7).

"Primero me gussaria saber quiénes fundaron los derechos humanos, quién es el grupo de personas que creó los derechos humanos... Ha de haber una o dos personas o tres personas que se inventaran eso y le vendieran la idea al grupo internacional y lo aprobaron." (GRUPO IO)

"Yo creo que aqui se puso de moda los derechos humanos, no sé si me equivoco, fue con Jimmy Carter. Jimmy Carter trajo una revolución de derechos humanos a El Salvador y lo que hizo fue hacer más revoltoso el pais." (GRUPO I0)

Tal como puede verse, este discurso extremo contra los derechos humanos viene de la mano de un fuerte nacionalismo que en último extremo puede desembocar en la teoría de la conspiración externa según la cual los derechos humanos habrían sido inventados por elementos extranjeros que lo habrían introdu- 
cido en El Salvador para dañar al país. Al concebirlos como algo no autóctono, como una intrusión externa, se socava así su universalidad y su legitmidad para ser aplicados en el país.

"Nosotros tenemos nuestra cultura ¿Y por qué otros países han querido venir a intervenir trayendo derechos humanos, verdad, cuando los derechos humanos han fomentado la delincuencia?" (GRUPO 10)

La queja fundamental se centra una vez más en la delincuencia, y en los derechos, excesivos a su juicio, que los derechos humanos han conferido a los delincuentes y que dificultan su persecución. En esto coinciden con la concepción definida en el epígrafe anterior, y tampoco comprenden porqué a los ciudadanos 'decentes' y a los delincuentes se les han de dar los mismos derechos. En esta cosmovisión maniquea de la sociedad, dividida en delincuentes y gente decente, en haraganes y gente productiva, las personas de este sector no pueden imaginar situaciones donde los derechos humanos pudieran defenderlos a ellos de atropellos por parte de otros. Así, se imposibilita una mínima empatra y se erosiona la universalidad de los derechos humanos.

Los derechos humanos no son comprendidos pues como derechos sino como una ideología y, en ocasiones, también se usan para designar simplemente a un grupo de personas. Según esta metonimia, los derechos humanos se reducirían a los individuos o grupos encargados de defenderlos.

"Si va un delincuente a poner su demanda, ese sí y ahi lo andan Ilos derechos humanos] hasta en los carros y lo andan asesorando en todo." (GRUPO (0)

Como consecuencia, muchos desearían acabar con la palabra 'derechos humanos' en aras de 'una terminología de hermandad' en la aparente creencia nominalista de que la eliminación del vocablo terminaría también con todas sus consecuencias políticas y sociales. Aunque más que nada están pensando en los derechos civiles y políticos cuando hablan de derechos humanos, e ignoran completamente a los derechos socio-económicos a los que obviamente no consideran como tales, su posición contraria a los mismos se trasluce cuando critican también la ayuda intemacional al desartollo, a la que culpan de volver a la gente haragana.

B) Atribuciones de responsabilidad por las violaciones

Aunque en su sentido estricto sólo el estado es responsable de las violaciones a los derechos humanos puesio que es el garante de los mismos, las concepciones que los distintos sectores sociales en El Salvador tienen sobre los derechos humanos son, como hemos visto, diversas y a menudo helerodoxas, por lo que las atribuciones que se hacen de responsabilidad no son tampoco siempre acor- 
des a su sentido estricto.

Las distintas atribuciones que se van a describir a continuación son un resumen de las respuestas obtenidas cuando el moderador planté explícitamente la responsabilidad por las violaciones anteriomente mencionadas. No son necesariamente incompatibles entre sí ni corresponden cada una a uno o varios grupos en exclusiva. Por el contrario, en varios grupos se encuentran varias de ellas simultáneamente, dependiendo de qué violación se trate, e incluso en ocasiones varias referidas a la misma violación.

La culpa por las violaciones a los derechos humanos es pues asignada a los siguientes elementos:

1. El estado, personificado a menudo en el gobierno, el presidente o en las autoridades locales. Esta es, con mucha diferencia, la atribución más común en casi todos los grupos, aunque como se describió anteriormente, en todos; los grupos culpan al estado de todos Ios tipos de violaciones. Es más usual en relación a los derechos civiles y políticos, y algo menos en lo que concirne a los sociales y económicos. Este último caso es más propio de los sectores más educados.

El grupo de orientación más derechistas (grupo 10) sólo menciona al estado a propósito de las violaciones a los derechos del niño.

2. La comunidad o los propios individuos. Esta autoatribución de culpa es corriente entre las comunidades marginales desorganizadas socialmente, con problemas internos y a menudo con un alto grado de anomía, donde los derechos humanos son entendidos en términos de respeto interindividual. Como esté respeto no siempre se da, la culpa recae obviamente sobre los individuos.

"Entre nosotros los pobres no nos queremos, entonces también no es cosa del gobierno, es cosa también de nosotros." (GRUPO 4)

"Como los ricos son unidos, nosotros los pobres también debemos ser unidos." (GRUPO 4)

Esta visión suele venir de la mano de una baja autoestima y una sensación de autodevaluación.

Por otro lado, en áreas donde la comunidad ha vivido históricamente sin el apoyo del estado (grupo 1), la responsabilidad por las violaciones a los derechos socio-económicos se proyecta sobre la propia comunidad o sus líderes.

3. Problemas sociales genéricos, como la pobreza, la guerra o la falta de educación. La mención de estas estructuras abstractas implica en realidad una difusión inespecílica de la responsabilidad o, en otras palabras, una incapacidad de encontrar un responsable concreto de las violaciones. 
"Todos lo entendemos cuáles son sus deseos, cuáles son los derechos del niño pero si no tenemos, cómo le vamos a complacer, verdad, cuando es que la pobreza es grande." (GRUPO 6)

"Los derechos humanos tienen que ser violados por la misma circunstancia de lo de la guerra y el país que no produce empleo." (GRUPO 5)

Este tipo de discurso se encuentra en áreas marginales, especialmente cuando no hay una organizacion social desarrollada, con frecuencia acompañado de una cierta dosis de fatalismo, pero también aparece en sectores de las clases medias remisos a señalar un culpable de las violaciones por miedo a parecer estar tomando una opción política determinada (grupo 8).

4. Valores sociales o ideologías, la más importante de las cuales es el machismo, al que se le culpa de buena parte de las violaciones que sufren mujeres y niños. Ocasionalmente, algunos sectores de mayor nivel cultural ofrecen alguna otra ideología como responsable de las violaciones.

"El principal violador de los derechos humanos es el programa económico neoliberal." (GRUPO 3)

5. Poderes o países extranjeros. Los sectores más derechistas atribuyen la culpa de las violaciones a los derechos - no digamos a los derechos humanos puesto que muchos incluso rechazan la palabra - al gobierno, pero sólo de manera indirecta puesto que su ineficacia se debería a los países extranjeros. Estos, que son precisamente los que insisten en los derechos humanos, tienen al gobierno atado de pies y manos. El mejor ejemplo de esto es, en su opinión, la lucha contra la delincuencia, ahora dificultada por el énfasis impuesto desde el extranjero en la delensa de los derechos de los delincuentes.

\section{C) Evolución de la situación de los' derechos humanos tras la guerra}

A la pregunta de cuáles han sido los cambios en las violaciones señaladas desde la guerra a la actualidad, la respuesta casi unánime es un notable descenso en las violaciones más gruesas, como al derecho a la vida o a la integridad personal, que eran consecuencia directa de la guerra o del clima político que la precedió y la causó y que, lógicamente, han de declinar con el fin del conflicto bélico y de la crispación concornitante.

La excepción a ese consenso es el grupo de orientación más derechista (grupo 10), pero incluso en esle grupo la fracción más moderada reconoce que la arbitrariedad y el militarismo propios de esa época anterior han disminuido.

"Por ejemplo el abuso que realmente había a nivel del militarismo aquí antes, hay que reconocerlo. Los derechos humanos [los] ha rebajado grandemente." (GRUPO 10)

Uno de los derechos civiles y políticos cuya recuperación es señalada de 
forma más unánime y destacada es la libertad de expresión, que se expande en la misma medida en que la publicidad de las opiniones propias no implica ya, al menos en la misma medida, una amenaza directa a la vida o a la integridad de la persona. Por tanto - un hecho es consecuencia directa del otro-, la disminución en las violaciones al derecho a la vida y a la integridad han permilido una mejora en la libertad de expresión puesto que a menudo el asesinato y la tortura se producían contra personas que habían expresado determinadas ideas $y$, con frecuencia, para evitar la propagación de tales ideas infundiendo el terror.

Con todo, a pesar de que hay un consenso en la mejora de la situación en este terreno, la situación dista de ser completamente satisfactoria.

"La libre expresión significa que por lo menos ya lo dejan hablar a uno. $O$ que alguien lo lleve y lo van a matar, por lo menos le dicen, mirá te matamos por esto, verdad." (GRUPO 8)

Para algunos sectores de la izquierda más militante, la guerra, consecuencia de la lucha de clases, continúa aunque con formas más suaves.

"Han habido cambios, pero son cambios que no llenan los requisitos para que nosotros podamos decir: estamos en paz." (GRUPO 2)

"En el sector de la construcción no hay paz laboral... aunque se pregone en los periódicos, se pregone en los libros." (GRUPO 2)

"Lo que está pretendiendo las catorce familias o los monopolios de nuestro medio es mantener y empezar a preparar en este caso ya no es una guerra militar o de cuestiones armadas, es una guerra psicológica." (GRUPO 3)

Estos mismos sectores denuncian que, aunque la represión contra los derechos básicos ha descendido mucho, no ha desaparecido del todo, sin embargo.

"Y aún ahora el nuevo método para mandar a matar a aquel que me está molestando, que va en contra de mis intereses es por medio de la violencia. Fingen que asaltan aquf al pobre compañero, le meten un par de balazos y es unos ricos que lo mandaron matar. $Y$ con la violencia sine como de pantalla." (GRUPO 3)

Por otro lado, el auge de la delincuencia impide que muchos sectores hagan un balance positivo de la evolución de las violaciones sufridas desde la guerra a la actualidad. Para algunos, la plaga de la delincuencia es concebida de hecho como otra guerra o como una continuación de la anterior.

"La guerra antes era entre el ejército y la guerrilla, y hoy es los delincuentes contra los ciudadanos." (CRUPO IO)

"Ellos /los delincuentes/ ya no están viviendo una vida humanitaria, 
ellos están viviendo una vida de machismo. Ya alli vamos viendo quién a quién, porque si yo tengo voy a responderles y si no tengo no les voy a responder, verdad. Entonces ellos lo que estín procurando es hacer la guerra de nuevo." (GRUPO 6)

Esta actitud es moneda corriente entre los sectores más derechistas, pero también en grupos sociales que, independientemente de su posición en la estructura social, vivieron relativamente cobijados de la guerra, bien por su modo de vida o bien simplemente por la parte del país en la que vivían. Para ellos, la guerra era un peligro del que era relativamente fácil prolegerse, alejándose de los frentes de combate y de los grupos en conflicto. En cambio, la delincuencia constituye una amenaza difusa, que afecta a todos y a nadie en particular, que puede producirse en cualquier momento y lugar, y de la que por tanto es dificil alejarse.

"Pero en lo que es a la seguridad pública, a la seguridad personal de las personas, a su propiedad, a su vida.. si como que este cambio de la guerra a la posguerra o a la paz, como que ha creado inseguridad por eso mismo, porque ya no se sabe de dónde viene la amenaza." (GRUPO 9)

"Mejor estuviéramos en guerra que en la posguerra porque la posguerra siempre es asi, es peor, es más peligroso, habiendo santo loco suelto." (GRUPO 9)

Esta atribución de la inseguridad a la locura subraya precisamente el carácter impredecible de la misma.

Por el contrario, quienes vivieron en áreas de conflicto o formaron parte de colectivos que sufrieron la represión, aun reconociendo el auge actual de la delincuencia y la inseguridad que comporta, no pueden por menos de percibir la situación actual como una clara mejora en la que los derechos básicos están mucho mejor salvaguardados.

Con sólo que se hayan terrninado las matazones asi, verdad, grandes, bueno con eso uno se conforma, verdad, pero ahorita lo que queremos es luchar porque se cumpla lo que a veces pedimos, lo que necesitamos." (GRUPO 4)

Uno de los elementos más importantes en este cambio de escenario es una mayor difusión y por tanto una mayor consciencia de los derechos humanos, tanto en cuanto a su contenido, como especialmente en lo referente al conocimiento de diferentes instancias a las que acudir en caso de violación.

"Anteriormente no sabíamos qué serán derechos humanos... Pensábamos que la violación sólo era una cosa, verdad, de matar a alguien." (GRUPO 1)

"Los derechos humanos para mi yo siento que es bueno... en realidad 
han hecho bastante, verdad, con apoyamos a nosotros... para que no seamos tan marginados que se diga. Tener esa libertad de expresión. Hoy nos sentimos bien porque bueno si nos hacen algo, nosotros nos vamos a ir a quejar a los derechos humanos, nos vamos a ir a quejar a la ONUSAL Entonces nosotros tenemos ese apoyo, esa libertad de decir nosotros tenemos con quién imos a quejar. Como antes no teníamos con quién imos a quejar, y nos hacian lo que nos hacian y no teniamos con quién irnos a quejar. " (GRUPO 4)

En resumen, el descenso de las violaciones más gruesas ha permitido la existencia y difusión de instancias de defensa de los derechos humanos que, a su vez, han contribuido a presionar para reducir las violaciones. Ahora, la gente, sobre todo los grupos organizados de izquierda, sabe mejor qué hacer y adónde ir en caso de ver atropellados sus derechos, y sabe también mejor cuáles son esos derechos.

Conectado con esto está la necesidad de potenciar la educación, en general y especificamente sobre derechos humanos, como modo de evitar las violaciones en el futuro -una idea común a casi todos los sectores, tanto conservadores como progresistas.

Hasta aqui, la referencia ha sido explícita o implícitamente a los derechos civiles y políticos cuyas violaciones constituyen de hecho a menudo los atropellos más graves. Sin embargo, la positiva evolución de estos últimos no viene acompañada de una mejora paralela en los derechos socio-económicos. En este caso, todos los sectores, al menos todos los sectores que sufren o reconocen violaciones en este terreno, manifiestan un estancamiento general. Los derechos socioeconómicos se encuentran, para muchas capas sociales, en el mismo estado de postración en el que siempre han estado.

"Si ha habido algún cambio [en los derechos socioeconómicos] ha sido quizás para beneficiar a los que ya estaban beneficiados... Pero los que realmente estaban adonde estaban antes, ahi siguen ahora o peor." (GRU.

PO 8)

En definitiva, el fin de la guerra ha traido una mejora, si bien no una solución total, a las violaciones a los derechos más básicos de la persona y a los derechos civiles en general. Otro tanto sucede, aunque en menor medida, en relación a los derechos políticos, pero el balance de los derechos socioeconómicos permanece igual de negativo que en el pasado. En este punto hay un alto grado de consenso general que incluye, con diversos matices, a grupos de izquierda organizada, a sectores marginales y a la clase media. Es decir, a la generalidad de la población excepto a los ambientes más derechistas, en los que como hemos visto se rechaza la misma noción de derechos humanos. 


\section{Estrategias e instancias de apelación para la defensa contra las violacio- nes a los Derechos Humanos}

En el discurso de los distintos grupos, especialmente cuando se les plantea qué hacen las víctimas, por un lado, y qué se podría hacer, por otro lado, ante las violaciones a los derechos humanos, pueden distinguirse las siguientes estrategias:

1. Resignación o lo que es lo mismo, ausencia de estrategia alguna para enfrentar las violaciones, tanto en cuanto a su conducta real como a su evaluación de la situación. En otras palabras, no sólo no han llevado a cabo ninguna estrategia de autodefensa en relación a las violaciones que han sufrido en el pasado sino que, cuando se les plantea la situación en términos generales, tampoco son capaces de sugerir ninguna. Esta actitud se encuentra fundamentalmente en comunidades marginales, tanto urbanas (grupo 5) como rurales (grupo 6), con escasa organización social y a veces un alto grado de anomía. Sus concomitantes psicosociales son el fatalismo y una baja autoestima. Este fatalismo implica que no tienen ninguna esperanza en las elecciones ni en general en el sistema político, ni en su forma actual ni en sus posibles desarrollos futuros.

"Al fin y al cabo, nosotros, sea él [el presidente] o sea otro, siempre sufrimos, nunca tenemos una felicidad que veamos un cambio sino que la misma cosa nos pasa. Vienen un presidente, otro presidente, no vemos un cambio, sino que... si viene algotro quizás pasamos un poco más terrible. Un cambio de ayuda, no. Un cambio puede haber, pero haciéndonos más que rodo el campesino sufre." (GRUPO 6)

Un buen ejemplo de esto en relación a los derechos civiles y políticos es la pasividad que en ciertas comunidades se produce ante la delincuencia, por miedo a represalias si uno denuncia los hechos. La anomía reinante, unida a la ineficacia e ilegitimidad de las autoridades ante las que tcóricamente se debería acudir, producen que la mejor opción parezca ser simplemente no hacer nada.

Por otro lado, en el lado de los derechos socio-económicos, encontramos comunidades donde la reacción ante la fluctuación especulativa de los precios de los productos agrícolas que cllos producen es simplemente cultivar más o menos terreno según el precio, y donde la pobreza parece cegar toda posible solución cuando sus miembros caen enfermos.

"Lo que hace uno es mejor cerrar las puertas /cuando ve que asaltan a alguien/ en lugar de irle a ayudar. Uno bien quisiera, verdad, pero lo que pasa que después toman represalias contra la familia de uno." (GRUPO 5)

"Algún día el niño se va a enfermar..., vamos a tener que fracasar porque no alcanzamos. No podemos robar, no podemos agarrar lo que no es de nosotros, cuando uno... le gusta respetar las cosas ajenas." (GRUPO 6) 
Es llamativo que los miembros de esta comunidad campesina, donde el alejamiento ha mantenido su modo de vida tradicional a pesar de la guerra pero también su marginalidad, manifiesten que ni siquiera la muerte de un hijo por falta de medicamentos es razón suficiente para quebrar las reglas interiorizadas de la moral social. Es un ejemplo extremo de resignación.

La primera causa para esta pasividad es Ia tradicional inoperancia y venalidad del aparato del estado, al que ya ni se molestan en recurrir. Esto produce una gran indefensión ante las violaciones, que no es remediada tampoco por ningún otro organismo.

"De quedamos callados es de que, pues si, ya no se siguen los problemas, verdad, ya no le hacen nada a uno. $Y$ de irlos a denunciar sería removerlos, o sea, sería como alargar el problema. Porque aunque uno los vaya a denunciar, hoy se los llevan presos, mañana los sacan, y saldrian sólo a matarlo a uno. De nada le sirve a uno ir a denunciar porque la verdad es que no le hacen nada." (GRUPO 5)

Por su parte, su imagen de los organismos no-gubernamentales, con los que tienen poco o ningún contacto, es un tanto difusa. Los organismos internacionales, como las Naciones Unidas, parecen ser contemplados por un modo ligeramente más positivo pero tampoco son vistos como una instancia alternativa de reivindicación. De hecho, hay comunidades que, en su aislamiento, no conocen prácticamente en absoluto a estos organismos ni su papel en el país (grupo 6).

Por otro lado, su falta de organización social y de una socialización política los aleja de las estrategias de reivindicación colectiva, como manifestaciones o huelgas, a las que contemplo con recelo.

2. Acción colectiva que consiste en la realización de manifestaciones, huelgas u otros medios de presión reivindicativa. Aquí se encuadra también la pertenencia a una organización (sindical, política, social), que suele ser un prerrequisito para poder llevar a cabo dichas acciones colectivas.

Como es predecible son los sectores de izquierda, asi rurales como urbanos, los que optan por este tipo de estrategias que de hecho han venido poniendo en práctica en su conflicto contra el estado, al que han estado enfrentado de manera más o menos activa. Al igual que en el caso de la resignación del epígrafe anterior, se trata no sólo de una estrategia que se propone para el futuro sino del modo habitual de reaccionar para este sector de la población.

"La huelga es la única arma que uno tiene como trabajador. Si no hubiera huelga no hubiera lucha." (GRUPO 2)

Es pues la opción preferida para los sectores de oposición, tanto si se trata de campesinos u obreros de clase baja como de universitarios de clase media, con ligeras diferencias en relación al énfasis puesto en unos aspectos u otros. Los 
sindicalistas, por ejemplo, ponen el acento en la importancia de una organización fuerte y solidaria. Son personas que en general identifican las violaciones, especialmente en el terreno de los derechos civiles y políticos, como un conflicto entre la ciudadanía (o al menos amplios grupos sociales dentro de la misma) y el estado (y los grupos que lo han apoyado y a los que éste ha sostenido). Al estado le atribuyen pues la plena responsabilidad de las violaciones. No hay que insistir, por tanto, en la ausencia de legitimidad que estas personas otorgan a un aparato de estado percibido como corrupto, al servicio de los poderosos y, en el mejor de los casos, ausente.

"Las formas legales, las formas normales que estén dentro del ordenamiento jurídico de nuestro país nunca están favorables a las grandes mayorías. Aqui siempre las cosas tienen que llevarse a la fuerza porque si no las grandes mayorías ya fueran todos en cadenas quizás para los Estados Unidos. " (GRUPO 3)

Estos sectores son los que más fe tienen en la lucha política como instrumento de cambio, los que más esperanza habían puesto en las elecciones, y por tanto los más alejados del fatalismo y la resignación ante las violaciones.

El uso de las acciones de presión colectiva suele venir acompañado por la apelación a organismos no gubernamentales o internacionales. Los sectores de izquierda suelen utilizar indistintamente ambas estrategias para presionar, directamente en el primer caso e indirectamente en el segundo, sobre el gobiemo. Esto es especialmente cierto cuando tales grupos han sufrido una larga historia de atropellos a sus derechos civiles y políticos por parte del estado, como por ejemplo es el caso de los antiguos refugiados, quienes gracias a sus propias protestas y a la mediación de organismos no gubernamentales y de las Naciones Unidas lograron una relativamente eficaz dinámica de autodefensa, incluso en medio del conflicto bélico.

La visión que eslos colectivos tienen de los organismos no gubernamentales es pues muy positiva, como instituciones cercanas a ellos que les han apoyado en momentos difíciles y cuya actuación ha evitado de hecho abusos aún más virulentos.

De igual forma, su percepción de la labor de las Naciones Unidas en el país es en general positiva, si no siempre por su desempeño concreto, sí por el efecto disuasorio de su mera presencia y por la influencia determinante que ha tenido para empujar al estado hacia una actitud más respetuosa con los derechos humanos.

"La presión intemacional tiene un gran valor aquí en nuestro medio, enorme pues, por la dependencia." (GRUPO 3)

Por su parte, los sectores conservadores se oponen, como era previsible, a este tipo de acciones reivindicativas, y la intensidad de su rechazo es proporcio- 
nal al grado de conservadurismo de su orientación política y a su pertenencia de clase. La postura más extrema (grupo 10) considera las huelgas y manifestaciones como los modos de actuación del enemigo, generadores de tensión social en vez de ser producto de la misma, y productores de pérdidas económicas. Fracciones de clases medias, de tendencia más bien conservadora pero sedicentemente equidistantes de los atropellos tanto del estado como de los que se rebelaron contra él (una fracción del grupo 8), aceptarían estas acciones reivindicativas sólo como un último recurso al que se recurre en su opinión con demasiada frecuencia. Se acuña incluso el término de libertinajes humanos' para hacer referencia al supuesto mal uso de las libertades recién conquistadas y avaladas por los derechos humanos.

"Aqui lo que se está haciendo y viendo ahorita no son derechos humanos ni libertades humanas sino que libertinajes humanos. Porque como no entienden tampoco y los habian tenido tapados de la boca y ahora que hablan, hablan y dicen grosería y media. " (GRUPO 8)

Otro elemento fundamental a la hora de determinar la reacción ante estas estrategias, aparte de la orientación ideológica, es el grado de organización social (política, sindical, etc.) de los colectivos a los que pertenece una persona y. conectado con esto, su experiencia previa de reivindicación grupal por medio de cualquier estrategia. Los grupos más desestructurados, incluso aquellos que no profesan tendencias conservadoras o son de extracción muy humilde, sienten desconfianza ante estos mélodos de acción directa, y manifiestan temer el desorden que éstos pueden generar. El mejor ejemplo de esta actitud lo encontramos en las zonas marginales, lanto rurales (grupo 6) como urbanas (grupo 5). La palabra recurrente en este discurso sobre las consecuencias negativas de las manifestaciones y las huelgas es 'alboroto', que refleja bien el miedo al caos sin un propósito claro y el miedo a la posible represión que estas acciones les inspiran.

En algunos grupos, de clase media o marginal, se dio un debate entre aquellos que destacaban las tensiones y los desórdenes producidos por huelgas y manifestaciones y los que defendían que no había otra alternativa pues otros modos más suaves eran ignorados y no daban ningún resultado.

"Si no escandalizan, no hay nada, pues, verdad. Porque por vía de la paz como acá en nuestro medio nunca se habian dado todo ese tipo de... Por lo general, pues, siempre han tenido que usar la violencia, pues, verdad. ... Un gobierno capitalisia como el de ellos siempre tratan la manera de defender sus intereses." (GRUPO 7)

"Estuve sindicalizado. Teníamos un secretario de conflictos, el hombre era el que ... solucionaba todas las cosas. No nos andaba involucrando que paremos ahora, que hagamos aqui, que hagamos allo, que vamos a 
manifestación. que apedreemos aqui, que matemos al policía. No. Iba a platicar con el gerente y si no ya arreglaba con el Ministerio de Trabajo. Ya esı́ solucionado, compañeros y ya íbamos a la Sociedad de Obreros, allí nos daban las charlas y ya qué es lo que se habia arreglado." (GRUPO 7)

Esta última cita, bajo la aparente moderación de la propuesta de un sindicalismo 'suave' y no participativo, refleja sin embargo la dureza de su posición y su rechazo a las acciones de masas - en las que ciertos sindicalistas 'involucran' a los demás - por la sorprendente facilidad con la que escala desde la huelga al asesinato de policías, como si este último fuera necesaria consecuencia de aquélla.

En ocasiones, los propios argumentos con que las clase media-alta critica a este tipo de acciones legitiman de manera indirecla e inconsciente el recurso a las mismas por las capas menos favorecidas.

"Lo que yo también pienso de eso, cómo va a creer si usted está ocupado, quiere sacar su carrera, quiere superarse y todo, cómo va a andar en manifestaciones perdiendo su tiempo, cuando puede estar estudiando. Para qué se va a ir a andar a darse duro con alguien que además su trompada la que le pueden dar. Que quedemos tranquilito en su casa y asegurando su futuro estudiando, superándose en vez de estar haciendo relajo." (GRUPO 9)

"La gente de otros estratos más elevados no va a andar en esas cosas Imanifestacionesl, ellos lo manejan a otro nivel, verdad, de burocracia o con loS amigos." (GRUPO 9)

Implícitamente, estas intervenciones ponen de relieve que quienes no tienen acceso a educación superior o no poseen contactos privilegiados con personas en el poder no parecen tener otra alternativa a la reivindicación colectiva directa.

3. Estrategias de intervención a largo plazo como la mejora de la educación de la población tanto en relación a los drechos humanos como en general. En este caso, no se trata por supuesto de estrategias que las vícticas de las violaciones adopten para obtener compesaciones sino de intervenciones globales que deberían producir un mayor respeto por los derechos humanos en el futuro. Ello sería así por diversas razones. Los posibles violadores y las víctimas potenciales tendrían un mayor conocimiento de los derechos en cuestión y estas últimas se scntirían además, en un clima de difusión general de tales derechos, en una posición más fuerte para reclamarlos.

"Las leyes son bonitas, verdad, pero ¿y si la persona no las conoce? ¿Y si la mujer no las conoce? Sigue aguantando. " (GRUPO 8)

"Una de las cosas que yo siendo que falla, falla un poco, es quizás eso. la falra de discusión de lo que es derechos humanos, en qué consisten los 
derechos humanos y cuándo alguien va a reclamar sus derechos". (GRUPO 8)

Además, parece existir la creencia de que un mayor nivel educativo en general contribuirá a una sociedad más justa y más respeluosa.

"Si el país no sale de su analfabetismo, nunca va a haber derechos humanos." (GRUPO 8)

En el caso de algunas violaciones especificas, la educación cumpliría un papel especial. Por ejemplo, hay un consenso amplio en que los atropellos contra las mujeres y los niños descenderían con una educación que contrarrestara el machismo tradicional.

En cuanto a la educación específica sobre derechos humanos, a menudo cada grupo la concibe haciendo énfasis en los derechos concrelos cuya violación más les preocupa.

"Eso es lo que ahora se esta tratando de hacer. De que nosostros inculquemos a nuestros niños los derechos humanos, el respeto a la propiedad privada 4 y toda esta clase de cosas que es bastante positivo y que nos llevan a una buena civilización." (GRUPO 9)

La importancia de la educción para la mejra de los derechos humanos se ve indirectamente confirmada por el hecho de que parlicipantes de diversos sectores (campesinos, marginales) perciben su bajo nivel cultural como un serio obsláculo en su intento de reivindicar sus derechos.

“No sabemos leer. Por eso nos enrollan fácil con engaños: esto tenés que hacer." (GRUPO I)

"Como no tenemos ninguna sabiduria, ningún estudio... Ah, bueno, lo que nos están diciendo es la verdad." (GRUPO I)

La falta de una educación formal es pues uno de los elementos fundamentales que está en la la base de la baja autoestima y autodevaluación que sufren diversos grupos y que, excepto en comuidades muy organizadas y militantes, conducen a la inactividad y a la resignación.

La insistencia en estas estrategias a largo plazo se da sobre todo en los sectores con mayor nivel educativo y cultural, tanto de izquierda (grupo 3) como conservadores (grupo 9), aunque también aparece ocasionalmente en sectores de las clases medias con menor nivel educativo (GRUPO 7 ).

En el caso de izquierda, estas estrategias son apoyadas junto a las manifestaciones y las huelgas, las primeras para incidir en el fuluro y las segundas para conseguir efectos inmediatos. Se trata pues de una complementariedad entre ambos modos de enfrentar las violaciones. 
En el caso de los sectores de clase media y media-alta conservadores, que forman un colectivo básicamente desorganizado, la mención a estas estrategias a largo plazo responde a su enfoque individualista de los problemas sociales en el que la acción colectiva no tiene cabida. La insistencia en una mejor educación como prerrequisito remite pues a una estrategia difusa en la que ellos mismos no parecen tener en realidad ningún papel activo. Serían los poderes públicos los encargados de suministrar esa mejor educación.

4. Tomarse la justicia por su mano Este tipo de actitudes aparecen normalmente referidas a la inseguridad provocada por la delincuencia y, obviamente, no se trata en realidad de un modo de disminuir las violaciones a los derechos humanos sino por el contrario de, pisoteando los derechos de otros, intimidar a pasados o posibles futuros agresores 0 , simplemente, de vengarse.

En diversos grupos aparecen, con mayor o menor sentido crítico, descripciones de estos comportamientos como reacción desesperada a un contexto anómico en el que el aparato de control formal del estado (policía, sistema judicial, etc.) no cumple su función de asegurar el imperio de la ley y de proteger al individuo,

"Yo creo es que por eso es que ahora la gente ha tomado la justicia en sus manos... porque saben que las autoridades en realidad no hacen nada" (GRUPO 8)

"Si me voy a quejar a algún lado que alguien me ha violado los derechos humanos, el fulanito puede conocer a alguien más alto y le dice: mirá que no me hagan nada a mi porque realmente no tuve la culpa. Total si yo no tengo dinero, no tengo palanca y no conozco a nadie, mi caso lo archivan y ahi queda.. Entonces de ahi viene la ley ojo por ojo y diente por diente, creo que esa es al única forma en que el salvadoreño ha podido sobrevivir." (GRUPO 9)

Se oyen inuluso voces lamentándose de que el mismo estado favorece estas opciones.

"Tenemos un sistema que está mal dirigido. Nos están llamando a que nosotros mismos nos defendamos." (GRUPO 9)

Es sin embargo en amplios sectores de la clase alta, muy conservadora, y ocasionalmente en fracciones también muy conservadoras de las clases medias - que comparten la convicción de que son los derechos humanos los que impiden una persecución adecuada de la delincuencia - donde se defiende activamente este tipo de soluciones.

"Las mismas autoridades le dicen a uno, me entiende verdad, porque hoy nosotros no podemos hacer nada por usted... Péguele un par de plomazos a alguien y digale ya estuvo.... Allí los derechos humanos tienen que actuar alli y ayudarle al que se defendió." (GRUPO 7) 
"Ahí si se están violando los derechos humanos porque han matado un ladrón [cuando el asaltado le dispara al ladrón]. Pero con la persona honrada no hay derechos humanos." (GRUPO 10)

En esta última cita parecerfa pues que el derecho de cada persona 'honrada' consistiría en poder matar a un ladrón.

Esta es la respuesta también a un escenario de absentismo e ineficacia del estado, pero en este caso por parte de las personas que en buena medida contaban con el poder de facto en este contexto (armas, vigilantes, contactos con autoridades, etc.). Como demuestra la última cita, una buena parte de este estrato social añora los tiempos en que se les permitfa ejercer su particular concepción de la justicia por su propia mano y aplicar la ley del más fuerte, tiempos que parecen haberse perdido ante la presión internacional y su nueva insistencia en los 'enojosos' derechos humanos.

\section{Representaciones sociales de los derechos humanos y estrategias para enfrentar las violaciones según la extracción social}

Este apartado trata de presentar las distintas visiones de los derechos humanos y de las estrategias para defenderlos, según el grupo social a que se pertenece, es decir, según la posición en la estructura social y las actitudes sociopolíticas dominantes. En otras palabras, es un intento de resumir los resultados de los diez grupos de discusión iniciales en agrupaciones más significativas, siendo más sintéticas, conserven sin embargo un razonable grado de homogeneidad. Según estos criterios, hemos distinguido cuatro estratos sociales:

1. La izquierda organizada. Personas pertenecientes a comunidades, sindicatos, organizaciones o partidos de izquierda, incluyendo a aquellos que sin pertenecer a ninguna organización concreta viven en este clima social o político y comparten sus aclitudes.

Aquí estarían encuadrados tanto comunidades campesinas con larga experiencia organizativa y de oposición (grupo 1) como miembros de sindicatos de clase (grupo 2); es decir la clase baja, tanto urbana como rural, con militancia política o social. También se incluirían sectores de clase media-baja y de clase media que comparten el mismo esquema valorativo (grupo 3).

Todos ellos parecen tener en común una visión relativamente ortodoxa de los derechos humanos, al menos en lo relativo a los derechos civiles y políticos, en términos de derechos del individuo que tienen que ser garantizados por el estado, único culpable pues de las violaciones. Se trata además de un estado al que han vivido enfrentados con mayor o menor virulencia desde siempre, y que perciben como violador de sus derechos más básicos, por lo que la defensa de los derechos humanos en general, especialmente para las personas de clase baja, ha tomado para ellos caracteres de autodefensa. 
Afirman sufrir numerosas violaciones, desde el derecho a la igualdad ante la ley hasta el derecho al trabajo, desde el derecho a sindicarse a la libertad de expresión, aunque algunas comunidades rurales, al haber vivido tradicionalmente tan alejadas del estado (grupo 1), no esperan ya de él una satisfacción activa de sus necesidades socioeconómicas sino más que nada un respeto a sus derechos civico-políticos. En este sentido, estas comunidades no conciben los derechos socio-económicos como tales derechos. Esta es la excepción, sin embargo, pues la mayoría reivindica estos derechos de forma activa sobre todo en las áreas urbanas.

Aunque todos reconocen una tremenda mejoria en el respeto a los derechos más básicos, consideran que la situación es aún muy insatisfactoria, especialmente en cuanto a los derechos socioeconomicos. Tanto es asf que amplios sectores mantienen que, aunque se haya firmado la paz, el conflicto prosigue de un modo u otro.

El aparato del estado, a quien consideran en cualquier caso un instrumento de la clase dominante que trata de explotarlos y controlarlos, no les inspira legitimidad alguna. Jueces, policías, funcionarios son definidos como ineficientes en el mejor de los casos y como corruptos y parciales en la mayoría de las ocasiones.

"El sistema judicial con sus fuerzas y juicios amañados hacen lo que ellos quieren con los trabajadores.." (GRUPO 2)

"Hoy los jueces que están van tras la mordida. Si usted le paga, al chile le hacen su caso... Deme trescientos pesos y ya estuvo. $Y$ van a traer al cliente bien socadito." (GRUPO 4)

Contra ellos emplean la movilización colectiva de sus organizaciones para ejercer presión sobre el poder público. Además, cuando se sienten atropellados acuden a los organismos no gubernamentales -que perciben como cercanos y siempre dispuestos a apoyarles - y a las instituciones intemacionales para completar esta presión sobre el gobierno. Sienten que ambos, pero sobre todo los primeros, han desempeñado un papel crucial para evitar mayores abusos durante el conflicto y consideran que la intermediación y el efecto disuasorio que supone la presencia de los segundos también ha sido, y es todavía hoy, crucial.

Su capacidad de resistencia ante las violaciones se basa por tanto en su organización social, cuya cohesión consideran muy importante. Dado que sus derechos son a menudo violados no en cuanto individuos aislados sino en tanto en cuanto pertenecientes a determinados grupos sociales, es decir debido a su pertenencia a los mismos, es precisamente como grupo tal como pueden defenderse y reivindicar sus derechos.

Conforman por tanto un colectivo bastante militante, que tiene puestas sus 
esperanzas en un cambio político y que aspira a una mejor situación en relación a sus derechos.

2. Los habitantes de arreas marginales, tanto urbanas como rurales, no organizados social ni políticalmente. Se trata de personas que viven en áreas de muy escasos recursos y servicios, en condiciones de extrema pobreza, y que además no poseen una organización social desarrollada. AsI, forman colectivos deprimidos económicamente y bastante desestructurados.

En el campo, encontramos poblaciones que han vivido tradicionalmente en este estado de extrema pobreza (grupo 6), mientras que en las ciudades es común que tales grupos se hallen en hábitats de viviendas provisionales (grupo 5) en núcleos de reciente creación, con población de aluvión a menudo desplazada por la guerra (grupo 4). Aunque a veces la población de estas áreas proviene de un mismo luyar desde el que se desplazaron colectivamente, es más común que tengan un origen heterogéneo que contribuye a su desestructuración.

Su falta de organización social suele venir de la mano de una ausencia no sólo de militancia política sino también de una identificación política definida.

Su concepción de los derechos humanos no está muy desarrollada y a menudo los conciben en términos de armonía interindividual, desvinculando por ello al estado de los mismos. Por otra parte, las violaciones de las que se quejan suelen referirse bien a problemas específicos que tienen, como la vivienda o la falta de regulación de precios por ejemplo, o bien a esa sensación de marginalidad traducida en cuestiones más difusas como la pobreza o la falta de respeto con que son tratados. También la inseguridad provocada por la delincuencia ocupa un lugar prominente ente sus preocupaciones. Paralelamente, la culpabilidad por las violaciones que sufren la atribuyen por un lado al gobierno, al poder político que no los saca de la marginalidad, pero por otro también difusas como la pobreza, lo cual no deja de ser una tautología pues las propias violaciones consisten en buena parte en su propio estado de extrema pobreza. Asimismo responsabilizan a los propios individuos por las violaciones, dentro de esa concepción de los derechos humanos como armonía interindividual.

La continuación de la pobreza y el incremento de la delincuencia hacen que el balance en la evolución del respeto a sus derechos sea de estancamiento, cuando no de deterioro, pese a que reconocen la mejora en cuanto a la libertad de expresión y al descenso del hostigamiento militar.

En el caso de las zonas rurales, a la marginalidad propia de su estatus socioeconómico se une la debida a su condición de campesinos, que se consideran relegados en la sociedad moderna.

"Si esto sigue asi como vamos, va a haber tiempo que nadie va a trabajar. ¿De dónde van a sacar maíz, frijoles, arroz? Y todo esto está afectando más que a todo a la nación." (GRUPO 6) 
"Pero el campesino no tienen validez ni lo atienden a uno." (GRUPO 6)

A pesar de esta queja del trato que reciben, la sensación de autodevaluación que ellos mismos sienten debido a su bajo nivel cultural contribuye también de manera decisiva a su marginalidad.

"A nosotros qué nos van a andar oyendo... como una gente que son preparadas y pueden ayudarle a uno a hablar o a expresarse lo que uno va a decir." (GRUPO 5)

La marginación sufrida y sentida, la baja autoestima y la falta de organización social se conjugan para producir una gran indefensión y desamparo. Sin poder recurrir a un aparato del estado que les resulta ajeno y al que ven como corrupto en general y como ineficaz o inviable para defender sus derechos socio-económicos, y con una imagen relativamente difusa de los organismos gubernamentales, su falta de organización social y de experiencia reivindicativa los aleja de las acciones colectivas de hecho. Sólo aquellos grupos que están fuertemente ligados a una organización social exterior, incluso si la propia comunidad presenta fracturas sociales importantes, recurren de hecho a marchas u otros tipos de movilizaciones colectivas (grupo 4).

Su imagen de los organismos internacionales como Naciones Unidas es en general favorable, pero no parecer saber muy cómo acudir a ellos o cómo pueden serles de utilidad.

En definitiva, la carencia de alternativas de reivindicación suele llevar a la resignación e inhibición, que a su vez lleva al fatalismo y a la falta de esperanza de cambio, no sólo mediante el actual sistema político sino en general. Alternativamente, algunas personas sienten que, en medio de una fuerte anomfa e inseguridad provocada por la delincuencia ante la que no hay respaldo institucional ( $\mathrm{ni}$ público ni por parte de organismos independientes ni por la propia organización comunitaria), la única estrategia posible es tomarse la justicia por su propia mano.

"Por lo general las personas ya no acuden a eso. Se lo hacen por su propia mano, pues. Porque como ven que aquello mejor lo archivan y lo van dejando hasta 15 años atrás. Dicen, no, yo si este me mata a mi hermano yo también le voy a dar." (GRUPO 5)

3. La clase media profesional sin una adscripción política clara. Su nivel cultural, relativamente elevado, contribuye a una visión bastante ortodoxa de los derechos humanos, que incluye tanto los derechos civiles y polf́ticos como los socioeconómicos y alribuye la responsabilidad de las violaciones al gobiemo.

Mencionan numerosos derechos concretos de ambos tipos como violados y su evaluación de la situación de los derechos humanos es en general bastante negativa. 
"Un pais que tradicionalmente ha sido analfabeto, que estuvo I2 años en guerra... que ahorita estamos en una posguerra, realmente derechos humanos aqui no se cumple ninguno." (GRUPO 8)

La evolución de esta situación de lu guerra a nuestros días les resulta positiva en cuanto a las libertades cívicas y políticas, marcadamente en cuanto a la libertad de expresión, pero estancada en relación al aspecto socio-económico.

Su representación de los derechos humanos y su evaluación de la situación son pues en buena medida convergentes con las de la izquierda organizada. Sin embargo, ambos sectores difieren marcadamente en cuanto a las estrategias para enfrentar las violaciones.

Su no pertenencia a organizaciones sociales o políticas, su ausencia de tradición reivindicativa en general, todo ello sumado al hecho de que su nivel de vida es más acomodado y de que las violaciones que sufren son mucho más livianas que las de otras capas sociales, no les hace proclives a las acciones colectivas de hecho. Es más, la fracción más conservadora contempla estas acciones (huelgas, manifestaciones, etc.) con sumo recelo y temen que ellas, y el desorden que supuestamente engendran, les traigan a ellos mismos más perjuicios que beneficios. Es en este grupo donde se acuña el término de 'libertinajes humanos' para referirse a los supuestos excesos generados por el 'mal uso' de la libertad conquistada al amparo de los derechos humanos, donde las demandas se disparan sin control.

La huelga, por ejemplo, que se considera un legftimo recurso pero sólo en último extremo, es percibida como un medio reivindicativo al que se acude con demasiada facilidad.

"La mayoría ocupan ya la huelga como único medio para poder presionar." (GRUPO 8)

En realidad, este tipo de personas hacen un esfuerzo más o menos consciente de equidistancia entre el aparato del estado, al que ven como ineficiente e incapaz de satisfacer los derechos de los ciudadanos (cuando no los reprime directamente), y la izquierda que se levantó, usando medios que ellos no aprueban, contra ese estado. Su opsoción de fondo a los métodos reivindicativos de la izquierda no obsta por tanto para que reclamen del estado un mayor respeto a los derechos humanos, tanto de ellos como de las capas más humildes. Desconfían de la política y de los políticos de cualquier signo, a quienes acusan de buscar el interés personal; constituyen en general un colectivo muy desestructurado y su capacidad de incidencia en la realidad social disminuye por este motivo.

Ellos se consideran pues 'en el medio', víctimas simultáneas de ambos bandos, tanto en la guerra como en la actualidad.

"Como antes no se podía decir nada y ahora pues se ha dados libertad 
de expresión, entonces la gente se va en desbandada y a decir todo lo que quiera y como quiera. $Y$ entonces si no tenemos educación tampoco para manifestarnos y para expresamos, entonces se viene el caos y volveremos otra vez a los problemas y a la represión. Y eso es lo que está sucediendo ahorita, de que vuelve la represión por la forma en que se está manifestando la gente. Aunque haya libertad de expresión pero como no lo está habiendo en la forma debida, lo tienen que volver a reprimir. Entonces volvemos como si fuera una nueda de caballitos la cosa, verdad. ... Y los que ni estábamos ni estamos,... nos pasan llevando. " (GRUPO 8)

En esta última cita se refleja la tendencia de la fracción más conservadora que llega a culpabilizar a las propias víctimas de las violaciones que puedan llegar a sufrir ('lo tendrán que reprimir').

Su percepción de los organismos no gubernamentales es que están sesgados hacia la izquierda, aunque les reconocen su labor de denuncia. Por otra parte, son críticos del papel de las Naciones Unidas aunque también admiten la importancia de su presencia. En ambos casos, no parecen ser instancias ante las cuales se sientan cómodos para apelar.

En lugar de estas reivindicaciones activas, este sector no propone otra cosa que la parálisis, aunque en este caso no tan fatalista como en la población marginal, o la insistencia en estrategias a largo plazo como la educación y la concienciación de la población. Se trata, como ya hemos visto, de un enfoque individualista, en el que no hay una aproximación colectiva ni una intervención propia en el problema sino una exigencia de una intervención pública cuyo efecto se dará en cualquier caso en el futuro. La falta de vertebración social de este colectivo contribuye a cegar otras posibles estrategias.

4. La clase media-alta y alta de inclinación conservadora o muy conservadora. Se trata de personas de estalus socio-económico alto, propietarios, comerciantes o profesionales de ingresos elevados, que se han identificado con la autoridad durante el conflicto bélico y profesan una ideología de derecha y nacionalista. Su nivel educativo es medio o alto.

Poseen una representación de los derechos humanos como un elemento negativo que en un determinado momento se introdujo en el país por medio de la presión externa, consiguiendo una gran influencia. Perciben la evolución de la situación desde la guerra a la actualidad como un empeoramiento, pues la delincuencia les resulta una amenaza mucho más difusa que la guerra por lo que es más difícil defenderse de ella. Algunos entienden el ascenso de la delincuencia como la continuación de la guerra, esta vez entre delincuentes y personas honradas.

Las capa.s más moderadas no rechazan los derechos humanos en sí mismos, cuya vigencia, e incluso cuyos efectos positivos contra la arbitrariedad y el 
militarismo también reconocen, sino que critican su manipulación a manos de la izquierda. Así, los derechos humanos habrían sido utilizados por la izquierda contra el gobierno y se habrían destacado siempre los atropellos gubernamentales pero no los de la guerrilla por ejemplo, que en su opinión son tanto o más graves que los primeros.

"Me gustaria es que si se tocarian sobre los derechos humanos, que se mire todo parejo. $O$ sea porque no es justo que digan unos: ay, que los derechos humanos, que no se qué y... capaz ellos atropellaron más derechos humanos que los que se le atropellaron a él mismo... Por ejemplo, lo sacan a bailar al Monseñor, a cada rato al pobre Monseñor sacan a bailar, que lo mataron, que no sé qué, que aquí, que allá, que no sé cuando. Y la gente tan buena que tenía tanto aporte para el país que mataron, nadie más se volvió a acordar. Por ejemplo el Chachi Guerrero, el señor Rodríguez Port." (GRUPO 9)

A juzgar por su postura se diría que piensan que la izquierda ha tenido bastante éxito en presentar esta imagen unilateral y sesgada, pues su discurso reacciona con imritación contra lo que parece la visión dominante. Las capas más educadas (grupo 9) se refieren sobre todo a este problema, la manipulación por la izquierda de los derechos humanos, y tienen un concepto algo más sofisticado de los derechos humanos. El otro elemento que les suele resultar inquietante en relación a los derechos humanos

El otro elemento que les suele resultar inquietante en relación a los derechos humanos es que conceden 'demasiados derechos' a los delincuentes, dificultando así su persecución, algo aún más preocupante con el incremento actual de la violencia. Esta actitud supone una negación del pensamiento democrálico y de la idea misma de los derechos humanos, puesto que rechaza la noción de que todas las personas deben tener los mismos derechos. Por el contrario, dicotomiza la sociedad en 'honestos' y 'delincuentes' y afirma que los segundos jamás deben tener los mismos derechos que los primeros y no debe perlnitírseles en cualquier caso usar tales derecho.s como escudos que eviten su castigo.

Sectores de las clases medias conservadoras comparten a veces esta crítica a los excesivos derechos de los delincentes (fracciones del grupo 7) y por tanto su renuencia al pensamiento democrático.

"Iban unos señores detrás de unos ladrones. Lo primero que le decía el delincuente, le decía, mire pero yo tengo mis derechos, le decía y ya verá le decía. Ensonces yo no sé pues hasta dónde, pues, los derechos humanos le proporcionan ayuda pues a ese tipo de gente, pues. " (GRUPO 7)

¿Hasta dónde llegan los derechos humanos, qué cobertura le dan a los ciudadanos para que tanso el delincuente como la persona honrada tengan los mismos derechos?" (GRUPO 7) 
El nacionalismo de las clases altas y medias-altas contribuye a su distanciamiento de la noción de los derechos humanos, a los que ven como importados del exterior y como un vehículo de presión de poderes internacionales sobre el gobierno de El Salvador, principal blanco de los reproches sobre atropellos y violaciones.

Las capas más extremas van más allá y su distanciamiento se convierte en abierta hostilidad contra la idea de los derechos humanos. Los derechos humanos no son vistos como tales derechos sino como una ideología de reciente creación destinada al beneficio de los izquierdistas y los delincuentes. A veces, el vocablo 'derechos humanos' es usado simplemente para definir a los individuos o grupos que se encargan de su promoción o defensa, en una metonimia que deja pocas dudas sobre el carácter partidista que le atribuyen al término.

"Y ayudarle al gobierno, no sólo a culparlo. Derechos humanos sólo lo que viene es a hincarle y a ponerle y que cumpla. Y cómo va a hacerle el gobierno para cumplirle todas estas grandes demandas que les vienen." (GRUPO IO)

Se oyen voces que quieren acabar con el mismo vocablo 'derechos humanos', en la creencia nominalista de que si se elimina la palabra desaparecerán los problemas que conlleva. En su lugar se deberían buscar otros téminos que llevaran menos a la confrontación.

"Aqui se han pisoteado más los derechos humanos pero si empezamos a hablar de eso, estamos hablando mal del gobiemo. Si hablamos que la delincuencia comete situaciones que van en contra de los derechos de otras personas, entonces estamos hablando también en contra de ellos. Aqui lo que hay que hacer es ya no hablar de derechos humanos $y$ buscar una terminología de hermandad." (GRUPO 10)

Para estas personas, se agudiza la convicción de que los derechos humanos 'dan demasiados derechos' a los delincuentes y los protegen de la acción de la justicia, pero se añade ahora la idea de que fueron creados expresamente con este fin de favorecer a delincuentes y subversivos -que son en último extremo la misma cosa - en su lucha contra la gente decente y productiva, contra ellos. Se extrema la percepción dicotómica de la sociedad en 'ellos' y 'nosotros'. No piensan que pueda haber ocasiones en que los principios contenidos en los derechos humanos les puedan servir a ellos mismos para salvaguardar sus derechos. Así, los derechos humanos se convierten en una pesadilla omnipresente, en una moda nefasta que sustituye las palabras y los modos de vida tradicionales.

"Todo el mundo se vale, pues, se quiere defender con los derechos humanos, ya no con las leyes civiles sino que derechos humanos. Son mis derechos humanos, son mis derechos humanos." (GRUPO 10) 
El nacionalismo, aún más fuerte en el caso de estas personas, unido a esta percepción de los derechos humanos como una imposicion externa, generan una teoría conspirativa, en la que los parses extranjeros habrían decidido dañar a El Salvador. Los derechos humanos habrian desempeñado un papel fundamental en esta estrategia de intrvención, control y destrucción a manos de los extranjeros.

"Se está viendo como que si esto lo quisieran llos extranjerosl desgarrar directamente, a El Salvador lo quisieran desgarrar. $Y$ con ese amparo de derechos humanos han venido a pisotear directamente." (GRUPO 10)

Somos infectados 6 por todos los extranjeros, perdone porque tenemos uno aqui, pero honestamente asi es, hablando de esto. Somos infectados por todos los extranjeros porque todos ellos quieren traer aqui lo que ellos saben hacer. ¿Y por qué? Desde cuando vino la Conquista nos vienen cambiando." (GRUPO 10)

El corolario de todo esto es la idea de que los principales males del país tienen su origen en el extranjero. De este modo, el nacionalismo consigue colocar la culpa fuera del país y afrontar un cierto complejo de inferioridad nacional, sobrecompensándolo, además de ofrecer una explicación para la impotencia que estas personas sienten ante la evolución de los acontecimientos políticos y sociales.

"Fue una guerra inyectada por los países poderosos para detenernos nuestro crecimiento. " (GRUPO 10)

Las estrategias que estos estratos sociales tienen disponibles para los casos en que ven sus derechos (no digamos sus derechos humanos puesto que muchos rechazan el término) son limitadas. Las acciones de masas son, por supuesto, absolutamente rechazadas como, en el mejor de los casos, una pérdida de tiempo y generadoras de disturbios, y en el peor, como un subproducto de la subversión. Son, al fin y al cabo, los métodos de "los otros', de la otra parte de la sociedad que está enfrentada a ellos en mayor o menor medida. Los organismos no gubernamentales son completamente asociados a la izquierda y a su estrategia y condenados en esa misma medida, de manera más contundente por los sectores más duros ('defienden a terroristas y delincuentes'). De igual forma, las Naciones Unidas son juzgadas con extrema severidad; la fracción moderada se acoge a cuestiones más o menos anecdóticas (algún caso de atropello de peatones y un caso de tráfico de drogas por miembros de ONUSAL) para justificar su rechazo, mientras que la fracción más extrema los asocia directamente a la izquierda y a la mencionada estrategia colonial de intervención extranjera en el país.

Sin embargo, no tienen el recurso a un estado al que tampoco ellos conceden legitimidad, lastrado por las corruptelas y la arbitrariedad de las que a veces ellos también son víctimas. 
"Nos vemos all que en cualquier momento por capricho de un uniformado nos quitan la placa, verdad. $Y$ eso es un derecho que nosotros tenemos que discutirlo. Pero por temor por la autoridad que ellos tienen, el poder, y porque ellos quieren cumplir un capricho de quien los manda, nos dejamos nosotrosejamos nosotros." (GRUPO I0)

"Nuestra sociedad así es, es de privilegios. Amigo de sutano y el que estaba de amigo con los del gobiemo pues está mejor que cualquier otro. Entonces y desde allí empieza la violación de derechos." (GRUPO 10)

Las fracciones más moderadas optan por estrategias de intervención a largo plazo, como la educación, y por la instauración de un verdadero estado de derecho que haga respetar la ley.

"Si hubiera una ley que ralmente va a juzgar a todo aquel que agarre el gatillo, yo estoy seguro que eso disminuiría bastante." (GRUPO 10)

Las más extremas, a menudo añoran el retorno a situación anterior en el que el absentismo y la falta de control del estado les permitra aplicar la ley del más fuerte y tomarse la justicia por su mano sin el engorroso freno de los derechos humanos.

“Ante cualquier ciudadano honrado o un comerciante o un industrial se podía defender de un asaltante. Y como no había ausoridad y todo eso. le podía disparar y bueno... Ahora no, ahora se va preso el comerciante o el industrial." (GRUPO IO)

\section{Conclusiones}

De acuerdo a la hipótesis de partida, se comprobó que los distintos sectores sociales en El Salvador tenían percepciones diferentes de los derechos humanos, hasta conformar representaciones sociales muy diversas y aun opuesta sobre los mismos. Estas representaciones encajan con el resto de la cstructura actitudinal y la cosmovisión de cada grupo, y también con su experiencia como actor en el conflicto político y social.

No se pretende que las representaciones que han sido halladas y relatadas en la presenta investigación agoten la totalidad de las que puedan darse en El Salvador, pero sí puede decirse que abarcan las percepciones sobre el tema de significativos sectores del país.

"Desde hace mucho tiempo, pues, no se hablaba nunca de los derechos humanos, ni siquiera la expresión de decir derechos humanos... Ha venido ahora con la discusión de lo que son los derechos humanos, como que se ha venido concientizando asi un poquito la gente a lo que tiene derecho." (GRUPO 8) 
Asimismo, parece haber consenso implícito sobre el hecho de que la preocupación por los derechos humanos y la importancia otorgada al término mismo han venido, al menos parcialmente, de fuera del pars. Esta 'llegada' de los derechos humanos y de los grupos que se ocupan de los mismos, que especialmente durante la guerra pasaron a un primer plano, es bienvenida por amplios sectores -especialmente de izquierda - como un gran apoyo para evitar los atropellos más gruesos, mientras que para los estratos conservadores y de clase alta su origen foráneo confirma su carácter de intrusos y la antipatia que sienten hacia los mismos. No es ajeno a ello la percepción de que gobiernos extranjeros han condicionado la ayuda económica o militar al cumplimiento de los derechos humanos, constiluyéndose éstos pues en un elemento de presión sobre el gobierno salvadoreño e hiriendo asf el orgullo nacionalista de la derecha conservadora.

En amplios términos, puede decirse que la noción de los derechos humanos desperita resonancias positivas en la izquierda y negativas en la derecha. Dos elementos resultan esenciales para condicionar el rechazo de esta última: las presiones externas sobre el gobierno -incluyendo aquí a las Naciones Unidas de forma destacada - relativas a los derechos humanos, vividas por ellos como un chantaje; y el aparente favor que los derechos humanos otorgan a los sectores de izquierda, quienes se quejan permanentemente de violaciones por parte del gobierno, y a los delincuentes, a quienes los 'excesivos' derechos otorgados impiden perseguir con eficacia. El hecho de que -de acuerdo a su significado estricto que no les es por otra parte familiar- el estado sea el único garante y por tanto el único violador de los derechos humanos, no impide que este sector, en un contexto tan polarizado como ha sido la guerra, perciba que tales derechos han servido mayoritaria e injustamente para poner de relieve los abusos de una parte, el gobierno, pero no de la otra. Los sectores más radicales no los consideran como tales derechos sino como una ideología contraria, y piden incluso la supresión del término. Por su parte, la izquierda sí los percibe como derechos y basa sus reclamaciones precisamente en la naturaleza 'legal' de los mismos.

De alguna forma, los derechos humanos parecen haber jugado un papel importante en el propio conflicto hasta haberse visto envueltos en los mismos frentes - cuando menos en el frente retórico- de batalla durante la última década.

Cabría añadir como consecuencia que, en la actual fae que vive el país, las campañas de educación sobre derchos humanos deberían contribuir a la desplarización de la percepcion de los mismos, acentuando su universalidad y tratando de convencer a los estratos más conservadores que la vigilancia sobre los derechos humanos también puede tener ventajas para ellos al garantizarles sus derechos.

En general, la representación de los derechos humanos en los diferentes grupos sociales no está demasiado cercana a la que se desprende de los convenios y los 
textos jurídico.s. Todavia muchos sectores no entienden los derechos humanos como una garantua debida por el estado a los ciudadanos, especialmente en lo que se refiere a los derechos socio-económicos. De hecho, diversos grupos, aun algunos de izquierda, no conciben como derechos más que los civiles y polfticos. Sólo la izquierda urbana más militante y las personas de mayor nivel cultural, independientemente de su ideología, manifiestan una representación más ortodoxa que incluye los derechos socio-económicos. En la mayorfa de los casos, el papel que se espera del estado es más bien el de un ente pasivo que respete derechos que el de un ente activo que haga lo posible por salisfacerlos. Las campañas de educación de los derechos humanos deberían por ende incidir preferentemente en esta área de los derechos socioéconómicos.

Las estrategias desarrolladas ante las violaciones a los derechos humanos vienen también en función de la clase social y la orientación política. El elemento que obtiene aquí un consenso casi absoluto es la percepción de ineficacia, cuando no de corrupción y favorilismo, que se tiene del poder público, especialmente en sus ramas ejecutiva y judicial.

"Las leyes acó bien se estiran y se encogen, pues, me entiende, ese es el problema que hay, pues, verdad, porque como dicen aqui el influyente es el que vale." (GRUPO 7)

Esto determina un alto grado de impunidad, indefensión y arbitrariedad, que son incluso denunciadas por los sectores más conservadores y de mayor estatus social. Como consecuencia, el grado de legitimidad atribuido al aparato del estado es casi inexistente, independientemente de la clase social y la inclinación política. Con un estado que no cumple su cometido, la vía del recurso ante los organismos públicos cuando se cometen atropellos contra los derechos humanos está casi cegada, excepto quizá en ocasiones por la mayor confianza depositada en la Procuraduría.

Sólo la izquierda organizada cuenta con una estrategia rápida para enfrentar las violaciones, que consiste en la presión por medio de la acción colectiva y del recurso a organismos no gubernamentales e internacionales. Tal estrategia se basa en la existencia de una fuerte organización social que les permite reaccionar como grupo a violaciones que sienten que sufren también en relación a su pertenencia grupal.

Los sectores más acomodados de las clases medias, que en cualquier caso sufren violaciones en menor grado, delienden estrategias a largo plazo coo la mejora de la educación. Por su parte, los sectores más derechistas sólo anhelan un mayor orden social, bien por un cumplimiento riguroso de la ley, que no se ha dado en el pasado, o bien por el recurso de tomarse la justicia por su mano.

La situación más desesperada corresponde a los habitantes de áreas marginales sin organización social, a quienes su desestructuración y su falta de una 
cultura y una experiencia reivindicalivas dejan a menudo en un estado de resignación, fatalismo y autodevaluación. Y ello es especialmente grave teniendo en cuenta que, pese a su frecuente incapacidad para identificar las violaciones y atribuir responsabilidad por las mismas, el nivel de atropellos que sufren es equiparable al de las clases bajas de izquierda.

\section{Notas}

1. Esta investigación es parte de un proyecto titulado 'Promoviendo la Defensa de los Derechos del Niño en el Salvador' desarrollado y financido por el Centro para el estudio de los Derechos Humanos de la Universidad de Columbia, Nueva York.

2. Vénse por ejemplo: Moscovici, S. (1961) La Psychanalyse, son image el son public. Presses Universitaires de France. Paris; o Moscovici, S. \& Hewstone, M. (1984) 'De la Science au sens commun' en S. Moscovici (ed.) Psychologie Sociale. Presses Universitaires de France. Paris.

3. Los subrayados son nuestros..

4. Los subrayados son nuestros..

5. Los subrayados son nuestros..

6. Los subrayados son nuestros.. 